\title{
Anisotropic deformation behavior under various strain paths in commercially pure titanium Grade 1 and Grade 2 sheets
}

\section{$\operatorname{AUTHOR}(S)$ :}

Yi, Ning; Hama, Takayuki; Kobuki, Akihiro; Fujimoto, Hitoshi; Takuda, Hirohiko

\section{CITATION:}

Yi, Ning ...[et al]. Anisotropic deformation behavior under various strain paths in commercially pure titanium Grade 1 and Grade 2 sheets. Materials Science and Engineering A 2016, 655: 70-85

\section{ISSUE DATE:}

2016-02-08

URL:

http://hdl.handle.net/2433/218275

\section{RIGHT:}

(c) 2016. This manuscript version is made available under the CC-BY-NC-ND 4.0 license

http://creativecommons.org/licenses/by-nc-nd/4.0/; The full-text file will be made open to the public on 8 February 2018 in accordance with publisher's 'Terms and Conditions for Self-Archiving'.; This is not the published version. Please cite only the published version.; この論文は出版社版でありません。引用の際には出版社版をご確認ご利用ください。 


\title{
Anisotropic Deformation Behavior under Various Strain Paths in Commercially Pure Titanium Grade 1 and Grade 2 Sheets
}

Ning Yi ${ }^{\mathrm{a}, \mathrm{b}}$, Takayuki Hama ${ }^{\mathrm{b}, *}$, Akihiro Kobuki ${ }^{\mathrm{b}}$, Hitoshi Fujimoto ${ }^{\mathrm{b}}$, Hirohiko Takuda ${ }^{\mathrm{b}}$ a. School of Materials Science and Engineering, Beijing Institute of Technology, Beijing 100081, China

b. Graduate School of Energy Science, Kyoto University, Yoshida-honmachi, Sakyo-ku, Kyoto 606-8501, Japan

\begin{abstract}
In this study, the anisotropic deformation behavior in commercially pure titanium Grade 1 and Grade 2 sheets under various strain paths was examined. A small but sharp stress peak arose during tension following compression in the Grade 1 sheet when loaded in the rolling direction, and the occurrence of a stress peak was retarded when the sheet was subjected to cyclic loading; however, such behavior did not occur in the Grade 2 sheet. Similarly, the work-hardening rate was different between the initial and latter stages of compression following tension. These behaviors did not arise when the sheets were loaded in other directions. The type of active twin mode was different depending on the loading path. When loaded in the rolling direction in both Grade 1 and Grade 2 sheets, $<10 \overline{1} 2>$ twinning and detwinning were active, respectively, during compression and tension following compression, whereas $<11 \overline{2} 2>$ twinning and detwinning were active during tension and compression following tension. The twinning activity was much more pronounced in the Grade 1 sheet than in the Grade 2 sheet. The abovementioned stress-strain responses were presumed to result from twinning and detwinning activities as for magnesium alloy sheets. However, we concluded that the effect of twinning activity on the stress-strain curves was much smaller in the titanium sheet than in magnesium alloy sheets.
\end{abstract}

Keywords: Commercially pure titanium sheet, Work-hardening, Anisotropy, Twinning, Detwinning

\section{Introduction}

Because of its good drawability, large elongation, high corrosion resistance, and high specific strength, commercially pure titanium (CP-Ti) is widely used in various industries including for aircraft, automobile, and biomedical applications. With the demand for products made of CP-Ti sheets in the aircraft and automobile industries increasing rapidly [1-3], the deformation behavior of CP-Ti has been studied widely [4-12].

CP-Ti exhibits strongly anisotropic-deformation behavior. One of the reasons of this behavior is that $\mathrm{CP}-\mathrm{Ti}$ is a hexagonal-close-packed (hcp) metal, and the critical resolved shear stresses (CRSS) and work-hardening differ significantly depending on the deformation mechanisms. The primal slip system in $\mathrm{Ti}$ is prismatic slip. In addition, basal slip and pyramidal slip are also active. In total, these three families of slip systems give 12 slip systems; however, only four independent slip systems exist in hcp structured CP-Ti because of the interaction between the prismatic and basal slip systems [4-5]. Some other slip systems, e.g., $<11 \overline{2} 3>$ pyramidal slip or twinning systems, such as $<10 \overline{1} 2>$ and $<11 \overline{2} 1>$ tensile twinning and $<11 \overline{2} 2>$ compressive twinning, are required to fulfill the von Mises criterion [6] at room temperature [7-8]. Among the several types of twinning systems, $<10 \overline{1} 2>$ twinning is the easiest to nucleate or grow [10-11]. Moreover, the microstructures, including the crystal orientations, grain size, and grain boundaries, also play vital roles in determining the mechanical behavior [13]. Many studies have been conducted to determine the

\footnotetext{
* Corresponding author. Tel.: +81 757535418; fax: +81 757535428.

E-mail address: hama@energy.kyoto-u.ac.jp (T. Hama).
} 
mechanical responses of CP-Ti under various loading conditions from both micro- and macroscopic viewpoints [14-19]. A literature survey on the previous studies is presented in our past paper [9]. Moreover, some other studies focusing specifically on the mechanical behavior of CP-Ti sheets under complex strain paths are introduced here. Low-cycle fatigue tests on a CP-Ti sheet were conducted by Sun et al. [12]. These authors reported that the cyclic hardening/softening behavior varied as the strain amplitudes and cycles changed. Similar results [20-23] were observed for Mg alloys, which have the same hcp crystal structure as Ti. Plane-strain compression tests were performed by Ayman et al. [14]. These authors reported that three stages of the work-hardening rate arose, and their mechanisms were analyzed based on the variation of the twin volume fraction. Stevenson et al. [19] reported that two modes of dislocation motions could be observed when samples were subjected to cyclic loading with various plastic strain amplitudes.

CP-Ti sheets are classified into several grades depending on the added amounts of oxygen and iron [24]: these amounts are at a minimum in Grade 1 sheets. The strength increases as the additive amounts increase; however, at the same time, the elongation decreases; thus, different grades are employed depending on the intended use [1-3, 25-27]. Among the grades, Grade 2 sheets are often used in manufacturing industries, such as in an automobile brake pad system or an exhaust system, because of the good elongation and relatively high strength of this grade [1-3, 25]. Therefore, the deformation behavior in Grade 2 sheets has been investigated extensively in past studies [9, 28-29]. In our previous study [9], the work-hardening and twinning behaviors under various loading paths in Grade 2 sheets were studied in detail. The in-plane anisotropy of the mechanical properties, such as the yield stress, work-hardening rate, and Bauschinger effect, was also examined. The twinning activity did not greatly affect the mechanical behavior in the Grade 2 sheet presumably because the twinning activity was not significant within the experimental condition we tested.

It is well known that the twinning activity increases as the additive amounts decrease [30]. Because the twinning activity in hcp metals plays a significant role in the deformation behavior such as the stress-strain curve and evolution of the Lankford value, as reported in previous studies on Mg alloys [20, 31-32], the deformation behavior in Grade 1 sheets should differ greatly from that of Grade 2 sheets. Thus far, most studies on Grade 1 sheets have focused on the mechanical properties under monotonic loading and their applications [33, 34]. For instance, Battaini et al. [35] investigated the effect of the loading direction on the mechanical properties under plane-strain compression in Grade 1 sheets and observed that the twinning activities and flow stresses were strongly dependent on the loading direction. In contrast, the mechanical behavior of Grade 1 sheets under complex strain paths such as reverse loading and cyclic loading has rarely been investigated. In addition, the difference in the mechanical behavior between Grade 1 and Grade 2 sheets is not yet understood.

In the present study, the difference in the mechanical behavior between CP-Ti Grade 1 and Grade 2 sheets is investigated in detail. To this end, the work-hardening and twinning behaviors in Grade 1 and Grade 2 sheets were examined under various loading paths using mechanical testing and electron backscatter diffraction (EBSD). The effect of the twinning activity on the work-hardening behavior in CP-Ti sheets is also discussed.

\section{Experimental Details}

\subsection{Materials}

In this study, cold rolled CP-Ti Grade 1 and Grade 2 sheets with thicknesses of $1 \mathrm{~mm}$ (Kobe Steel) 
were used. The samples were prepared along the rolling direction (RD), transverse direction (TD), and $45^{\circ}$ from the RD, as illustrated in Fig. 1 (a). Hereafter, these samples are referred to as RD, TD, and $45^{\circ}$ samples, respectively. The shape of the samples is shown in Fig. 1 (b). The samples were annealed at $530^{\circ} \mathrm{C}$ for $1 \mathrm{~h}$ before the tests discussed below.

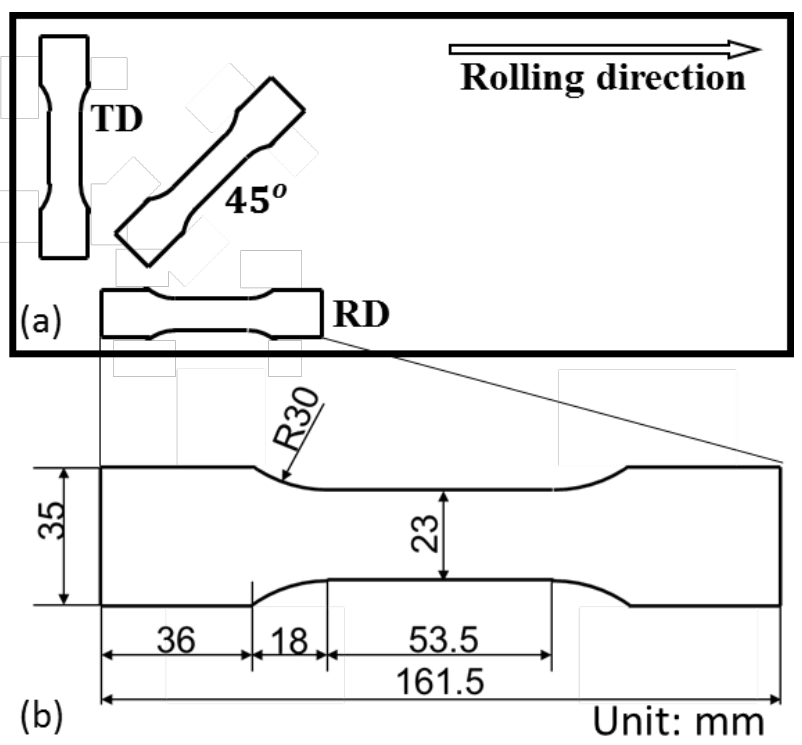

Fig. 1 Illustration of (a) sample preparation and (b) sample geometry.

\subsection{Experimental Procedures}

To study the deformation behavior under various loading paths, monotonic tension, monotonic compression, reverse loading, and cyclic loading tests were performed. To prevent buckling during in-plane compression of the sheets, comb-shaped dies were utilized to apply compressive forces through the thickness. The experimental apparatus and comb-shaped dies were the same as those used in our previous works [9, 21]. A compressive stress of 3.6 MPa was applied to the thickness direction of the sample. Molybdenum disulfide (Moly paste, Sumico Lubricant Co.) was used for lubrication between the sample and comb-shaped dies; this lubricant differed from that used in our previous study, mineral hydraulic oil [9]. The new lubricant was used because it was expected that molybdenum disulfide could provide better lubrication than mineral hydraulic oil. Because of this change, the mechanical tests performed on the CP-Ti Grade 2 sheet were conducted again to unify the experimental conditions even though most of these results were reported in our past paper [9]. Nevertheless, the tendencies observed in the stress-strain curves remained unchanged from those reported in our past paper. A strain gage (KFEM, Kyowa Electronic Instruments) was used to measure the strain during the test. The initial strain rate was set to $6.67 \times 10^{-4} / \mathrm{s}^{-1}$ as in our previous study [9].

The experimental conditions for reverse loading were as follows. As for the tension-compression (TC) test, a tensile pre-strain of either 0.05 , 0.1 , or 0.2 was applied, and then, a compressive strain of 0.15 was applied after the loading direction was inverted. However, in the compression-tension (CT) test, a compressive pre-strain of either $0.05,0.1$, or 0.15 was imposed followed by tension to a strain of 0.15 .

The cyclic loading test was performed with a strain amplitude $\varepsilon$ s $=0.1$ or 0.05 after a pre-strain $\varepsilon 0=$ $-0.055,-0.03,0,0.03$, or 0.055 was imposed. The RD samples were used in the cyclic loading test.

After the mechanical tests were conducted, the microstructures were examined using EBSD to observe the texture evolution and twinning activity. The cross-sectional surfaces perpendicular to the loading 
directions were measured. The measurement results were qualitatively independent of the cross-sectional surface, e.g., the measurement results were almost the same on the RD and TD surfaces. The surfaces were polished using a cross-section polisher before the measurement. Magnification of 500x and a step size of 1.0 $\mu \mathrm{m}$ were applied for all the conditions. The pole figure (PF), inverse pole figure map (IPF map), and extracted twin boundaries were analyzed using OIM-Analysis 7 (TSL Solutions). As in our previous study [9], measured data with confidence index smaller than 0.1 was excluded before analysis. Because the stressstrain curves for the Grade 2 sheet obtained in the present study were in good agreement with those of the past study as mentioned before, we assumed that the texture evolution and twinning activity would also be almost the same between the present and past tests; thus, the EBSD analysis was performed only on the Grade 1 sheet in the present study.

\section{Experimental Results}

\subsection{Monotonic tension and compression}

The mechanical properties of the Grade 1 and Grade 2 sheets obtained under monotonic tension are summarized in Table 1. Compared with the Grade 1 sheet, the Grade 2 sheet exhibited larger strength and smaller total elongation. These tendencies are independent of the loading directions. For both the Grade 1 and Grade 2 sheets, the TD sample exhibited the largest $0.2 \%$ proof stress, the RD sample exhibited the largest tensile strength, and the $45^{\circ}$ sample exhibited the largest total elongation. Interestingly, for the Grade 1 sheet, the TD sample exhibited much smaller fracture strain than that of the RD and $45^{\circ}$ samples.

Table 1 Mechanical properties of CP-Ti Grade 1 and Grade 2 sheets.

\begin{tabular}{ccccccc}
\hline & & Grade 1 & & \multicolumn{3}{c}{ Grade 2 } \\
& RD & $\mathbf{4 5}^{\circ}$ & TD & RD & $\mathbf{4 5}^{\circ}$ & TD \\
\hline$\sigma_{0.2} / \mathrm{MPa}$ & 153 & 183 & 203 & 277 & 301 & 314 \\
$\sigma_{\mathrm{T}} / \mathrm{MPa}$ & 303 & 261 & 273 & 408 & 387 & 391 \\
$A / \%$ & 65.5 & 67.0 & 56.8 & 38.7 & 42.5 & 41.5 \\
$A_{\mathrm{u}} / \%$ & 42.6 & 17.6 & 11.9 & 15.2 & 11.3 & 9.9 \\
\hline
\end{tabular}

$\sigma_{0.2}$ stands for proof stress, $\sigma_{\mathrm{T}}$ stands for tensile strength, $A$ stands for total elongation, and $A_{\mathrm{u}}$ stands for uniform elongation.

To investigate the work-hardening rate of the Grade 1 and Grade 2 sheets during tension and compression, the absolute true stress-absolute logarithmic strain curves up to an absolute strain of 0.1 are presented in Fig. 2. For a better comparison of the work-hardening rate between the Grade 1 and Grade 2 sheets, the variation of the work-hardening rate $[9,36]$ as a function of the absolute logarithmic strain is displayed in Fig. 3. The work-hardening rate was calculated using 2 points of every 500 data points. Note that the small oscillation observed in the evolution may be due to the friction between the samples and comb-shaped dies. The work-hardening rate decreased sharply at the beginning of plastic deformation and then decreased gradually until the end of the deformation. This tendency is the same under both tension and compression and is independent of the samples. Zooming in on the curves in the strain range from 0.02 to 0.09, the Grade 2 sheet exhibits a slightly larger work-hardening rate than the Grade 1 sheet for all three orientation samples and for both tension and compression. The difference in the work-hardening between the Grade 1 and Grade 2 sheets may result from the mass fraction of oxygen being larger in the Grade 2 sheet 
than in the Grade 1 sheet, which causes lattice distortion and increases the resistance of dislocation motion [37] and eventually leads to a larger work-hardening rate. Moreover, the difference in the grain size, i.e., the grain sizes are approximately 35 and $20 \mu \mathrm{m}$, respectively for the Grade 1 and Grade 2 sheets, would also produce such a difference in the work-hardening rate.

Fig. 3 (c) compares the work-hardening rates between tension and compression for the RD sample of the Grade 1 and Grade 2 sheets. The work-hardening rate is slightly larger under compression than tension in the Grade 1 sheet, whereas the difference in the work-hardening rate is negligible in the Grade 2 sheet.
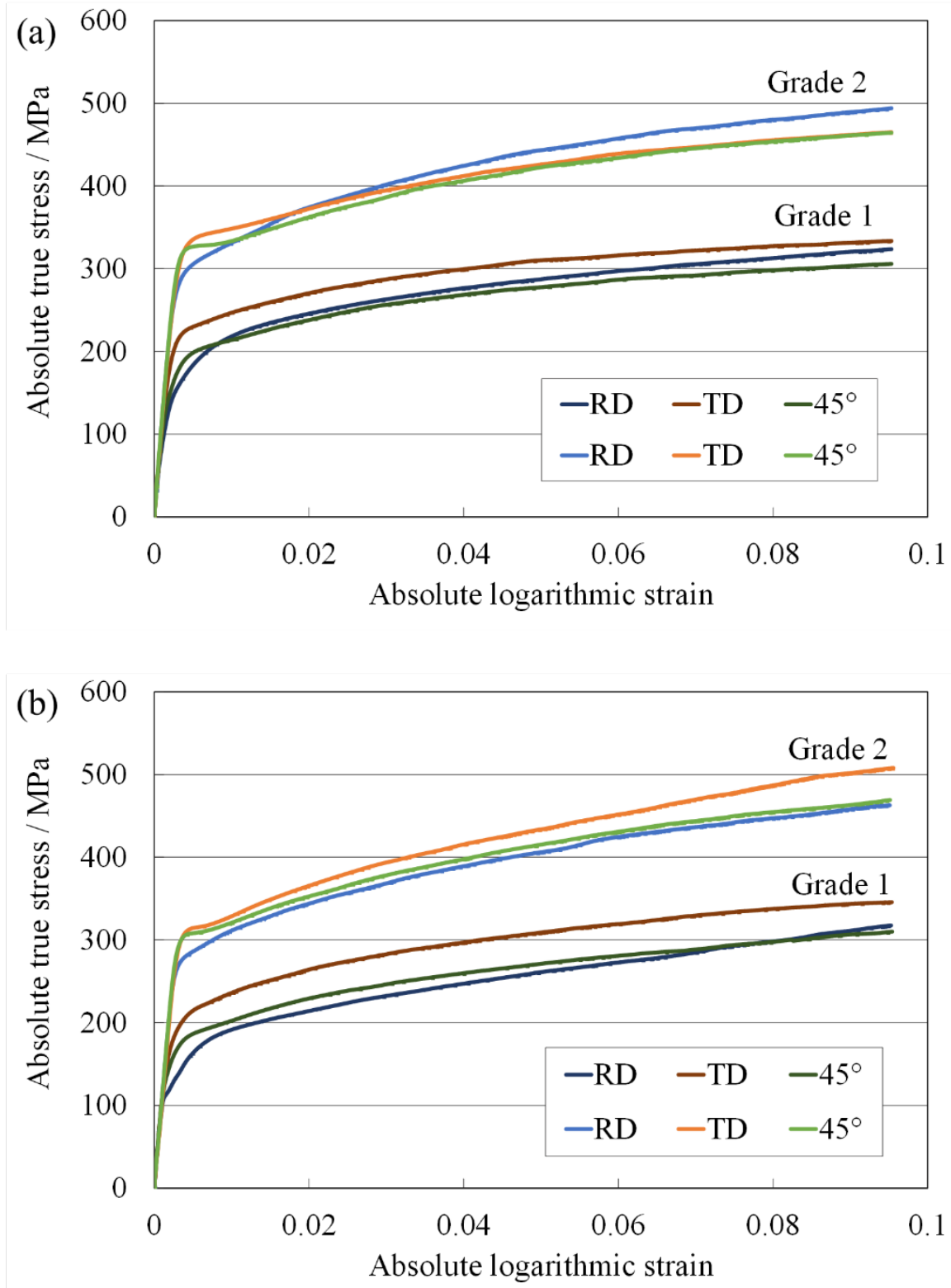

Fig. 2 Absolute true stress-logarithmic strain curves under (a) tension and (b) compression. 

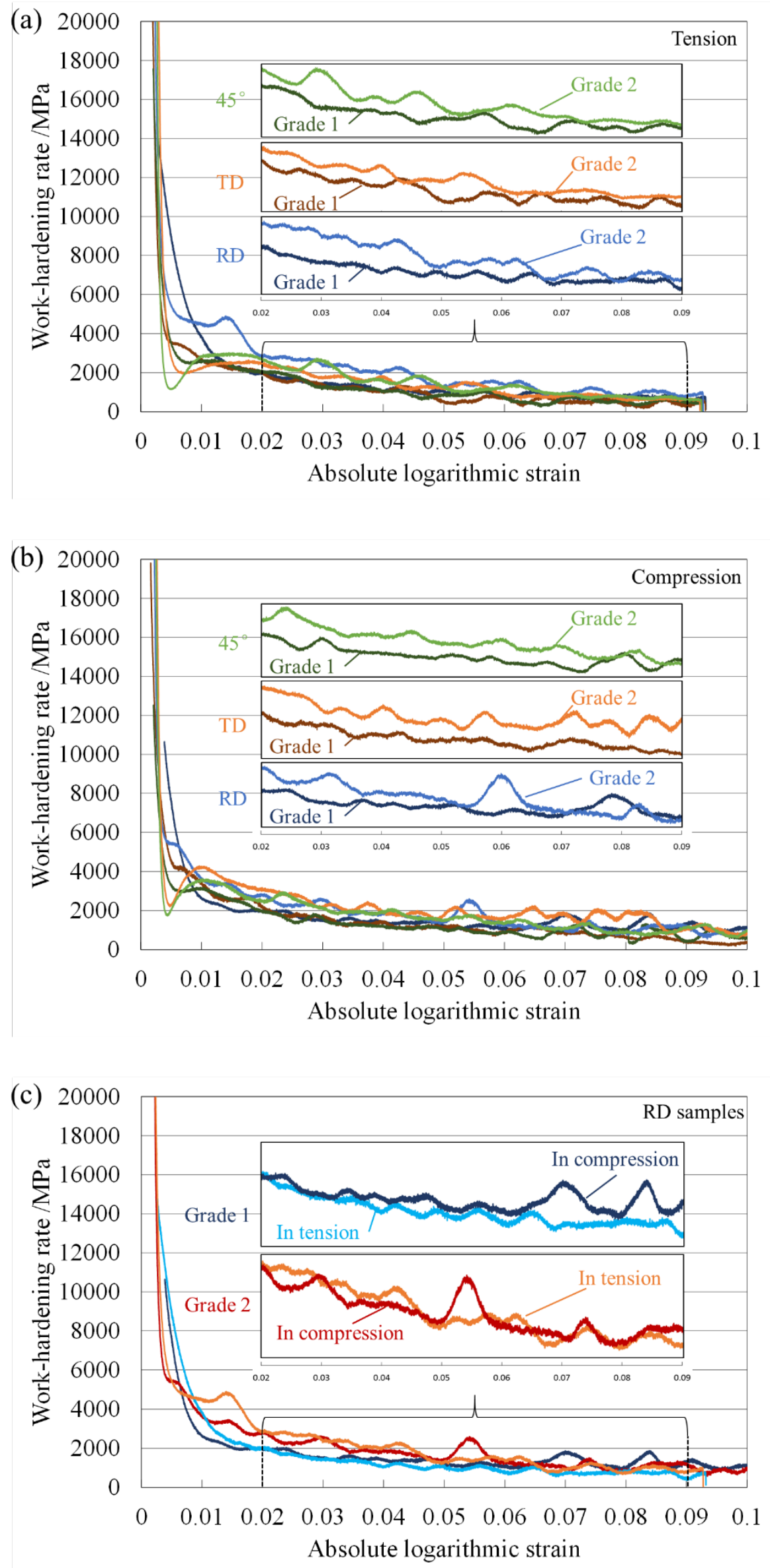

Fig. 3 Variations of work-hardening rate as a function of absolute logarithmic strain in the Grade 1 and Grade 2 sheets during (a) monotonic tension and (b) monotonic compression. (c) Comparison between tension and compression in the RD samples. 


\subsection{Reverse loading}

Fig. 4 presents the true stress-logarithmic strain curves obtained under CT and TC in the Grade 1 sheet. To examine in detail the change in the work-hardening rate after the strain reversal, Fig. 5 displays the evolution of the absolute work-hardening rates as a function of the absolute logarithmic strain after the strain reversal. Note that small necking occurred during tension under CT in the TD and $45^{\circ}$ samples. This trend has a high correlation with the finding that the uniform elongation under monotonic tension is small in these samples, as observed in Table 1. Furthermore, TC with a tensile pre-strain of 0.2 could be performed only for the RD sample because necking occurred during tension in the TD and $45^{\circ}$ samples; thus, a reverse loading test could not be conducted for these samples.

Interestingly, a small but sharp stress peak (stage Q in Fig. 4 (a)) appears during tension under CT in the RD sample. This stress peak occurs irrespective of the pre-strain. This tendency can also be observed in the evolution of the work-hardening rate (Fig. 5 (a)): the RD sample exhibits a sharp increase and drop in the work-hardening rate regardless of the pre-strain. The sharp change in the work-hardening rate becomes clearer as the pre-strain decreases. However, this stress peak is not observed in the TD and $45^{\circ}$ samples (Fig. 5 (b)).
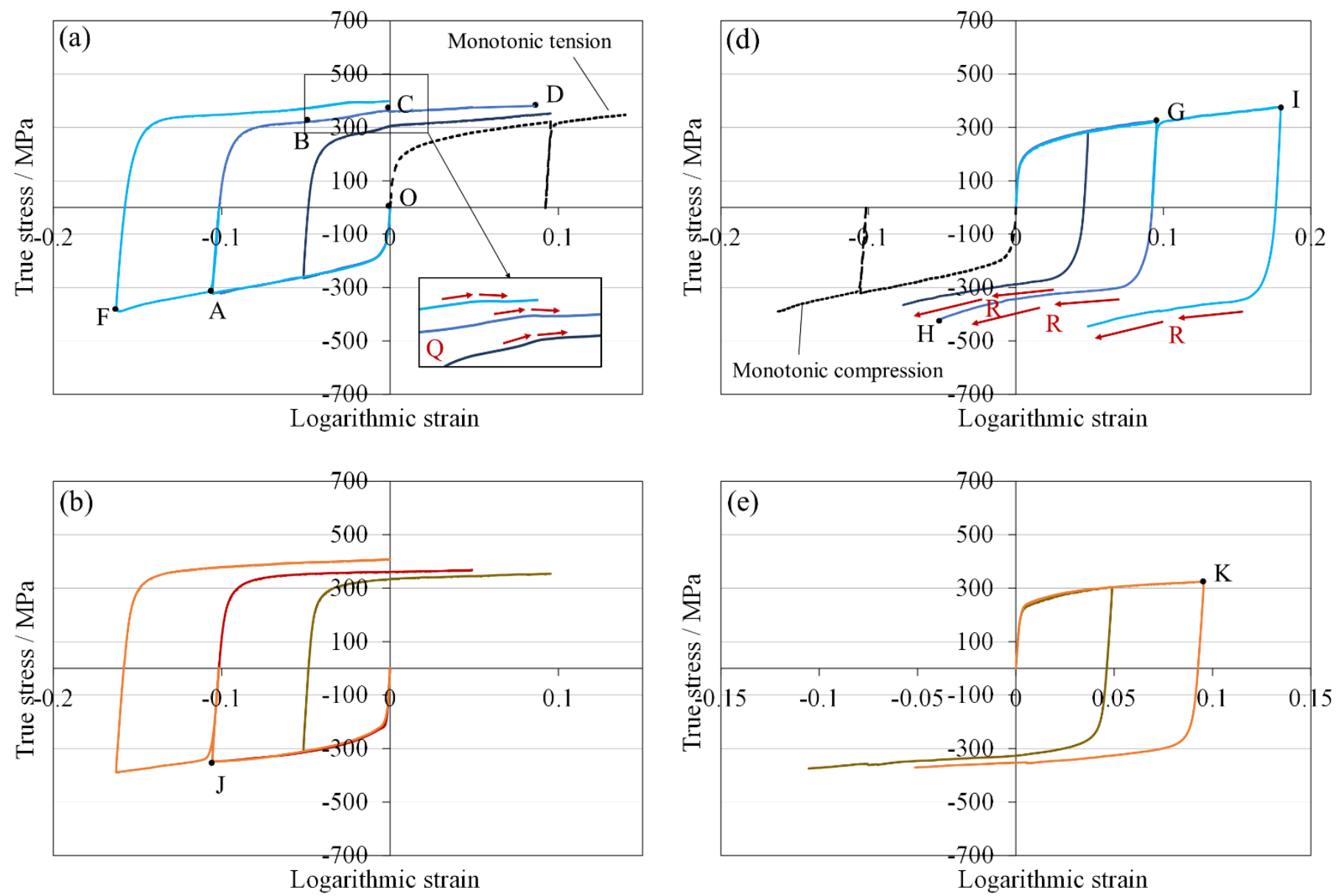

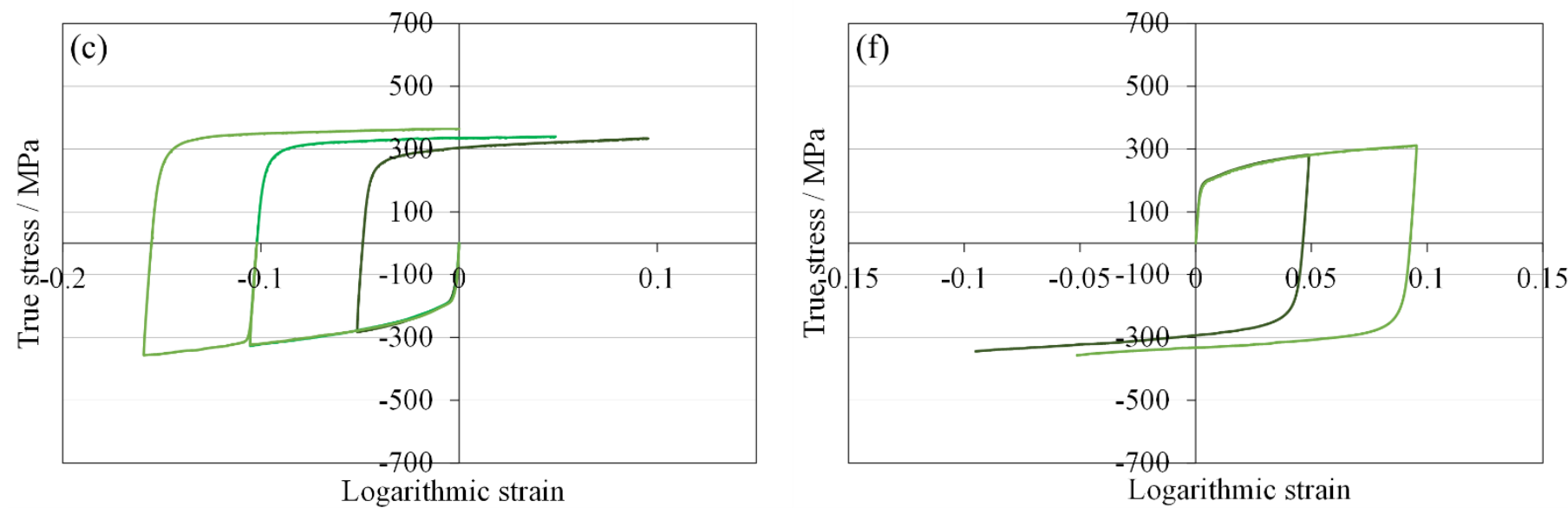

Fig. 4 True stress-logarithmic strain curves obtained under reverse loading in the Grade 1 sheet. (a) CT in RD sample, (b) CT in TD sample, (c) CT in $45^{\circ}$ sample, (d) TC in RD sample, (e) TC in TD sample, and (f) TC in $45^{\circ}$ sample.
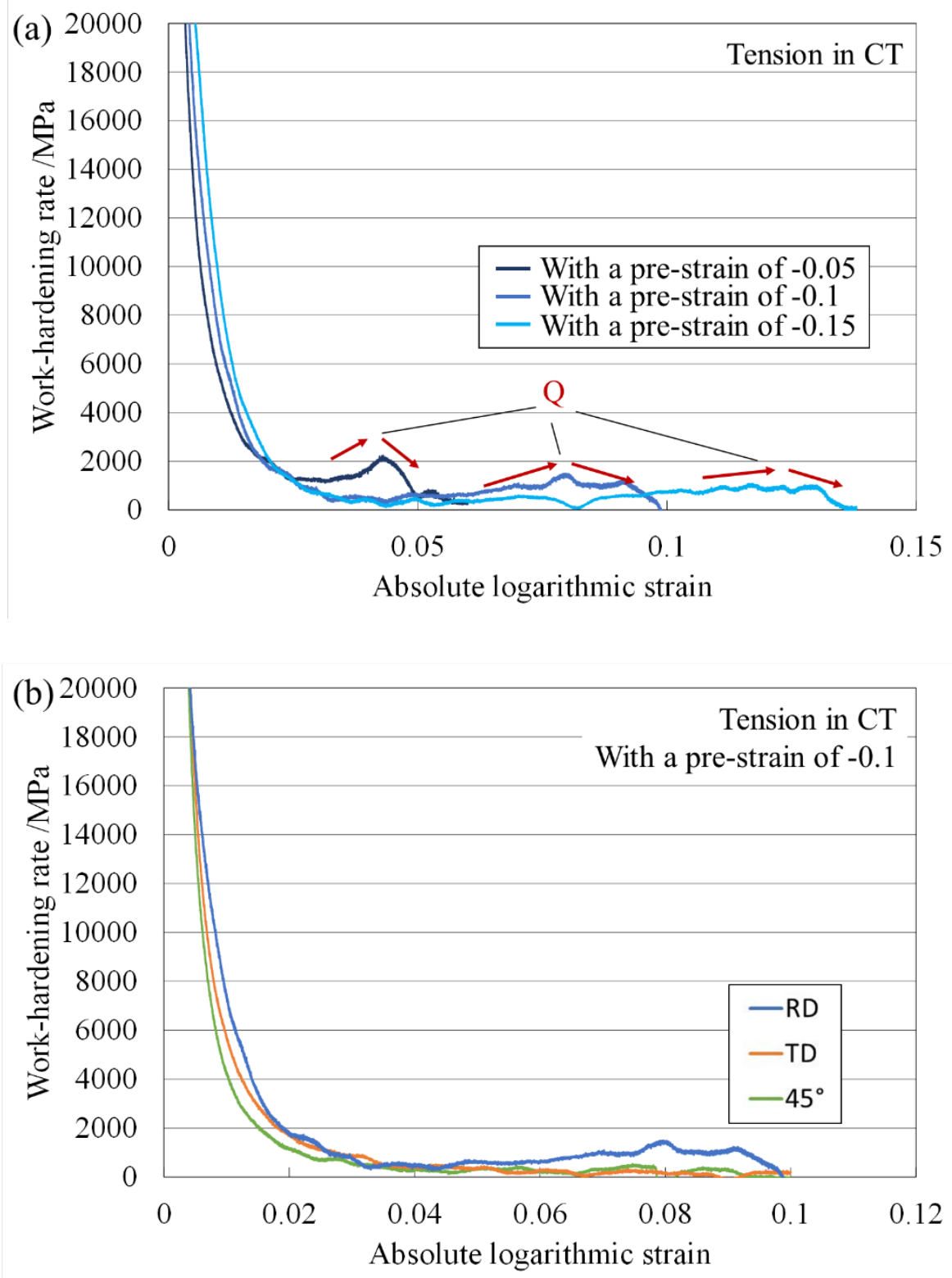

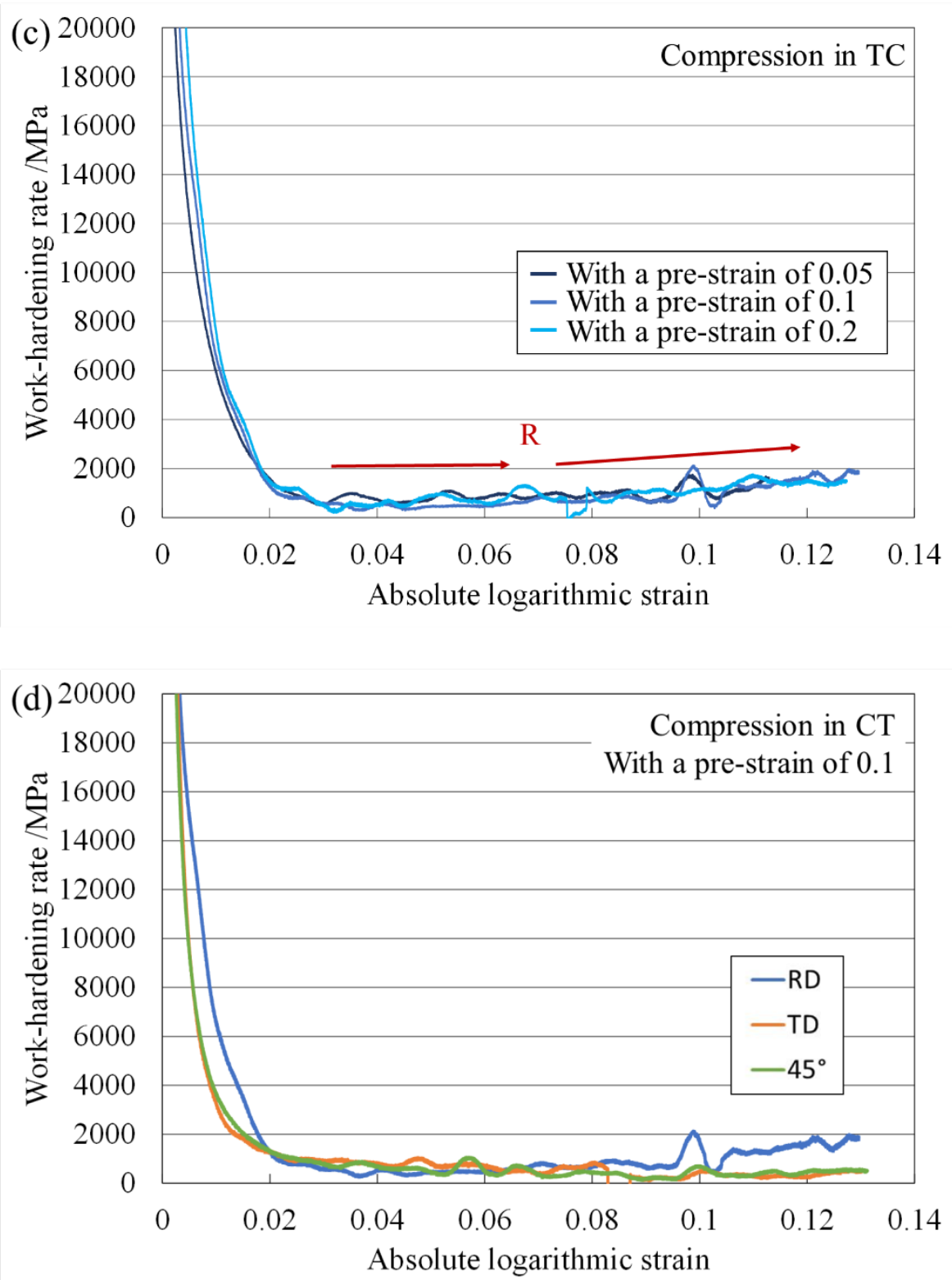

Fig. 5 Variations of work-hardening rate as a function of strain after strain reversal in the Grade 1 sheet. (a) CT in RD samples (b) CT with a pre-strain of -0.1 in RD, TD and $45^{\circ}$ samples (c) TC in RD samples, and (d) TC with a pre-strain of 0.1 in $\mathrm{RD}$, TD and $45^{\circ}$ samples.

This stress peak does not occur irrespective of the condition under TC. Additionally, the work-hardening behavior is different depending on the sample. In the RD sample (Figs. 4 (d) and 5 (c)), the work-hardening rate increases gradually during the initial stage, whereas it increases rapidly in the latter stage (stage $\mathrm{R}$ ). This change in the work-hardening rate occurs irrespective of the pre-strain under TC but does not occur under monotonic compression. However, this tendency is not observed and the work-hardening rate decreases gradually throughout the process in the TD and $45^{\circ}$ samples (Fig. 5 (d)). The abovementioned tendencies are independent of the pre-strain.

Fig. 6 displays the true stress-logarithmic strain curves obtained under CT and TC in the Grade 2 sheet. Compared with the results for the Grade 1 sheet (Fig. 4), a sharp stress peak does not appear during tension under CT in any of the samples. Additionally, the following trend is observed in the RD samples. During TC with a pre-strain of 0.2 (Figs. 6 (d)), the increase in the flow stress is very small during the initial stage, whereas it becomes relatively large in the latter stage (stage T) similar to the stage R in Fig. 4 (d). In contrast, 
the increase in the flow stress is almost constant throughout the process with a pre-strain of 0.05 or 0.1 (stage U). In the TD and $45^{\circ}$ samples (Figs. 6 (e) and 6 (f)), the tendency in the stress-strain curve is similar to that of the RD sample with a pre-strain of 0.05 or 0.1 irrespective of the pre-strain.
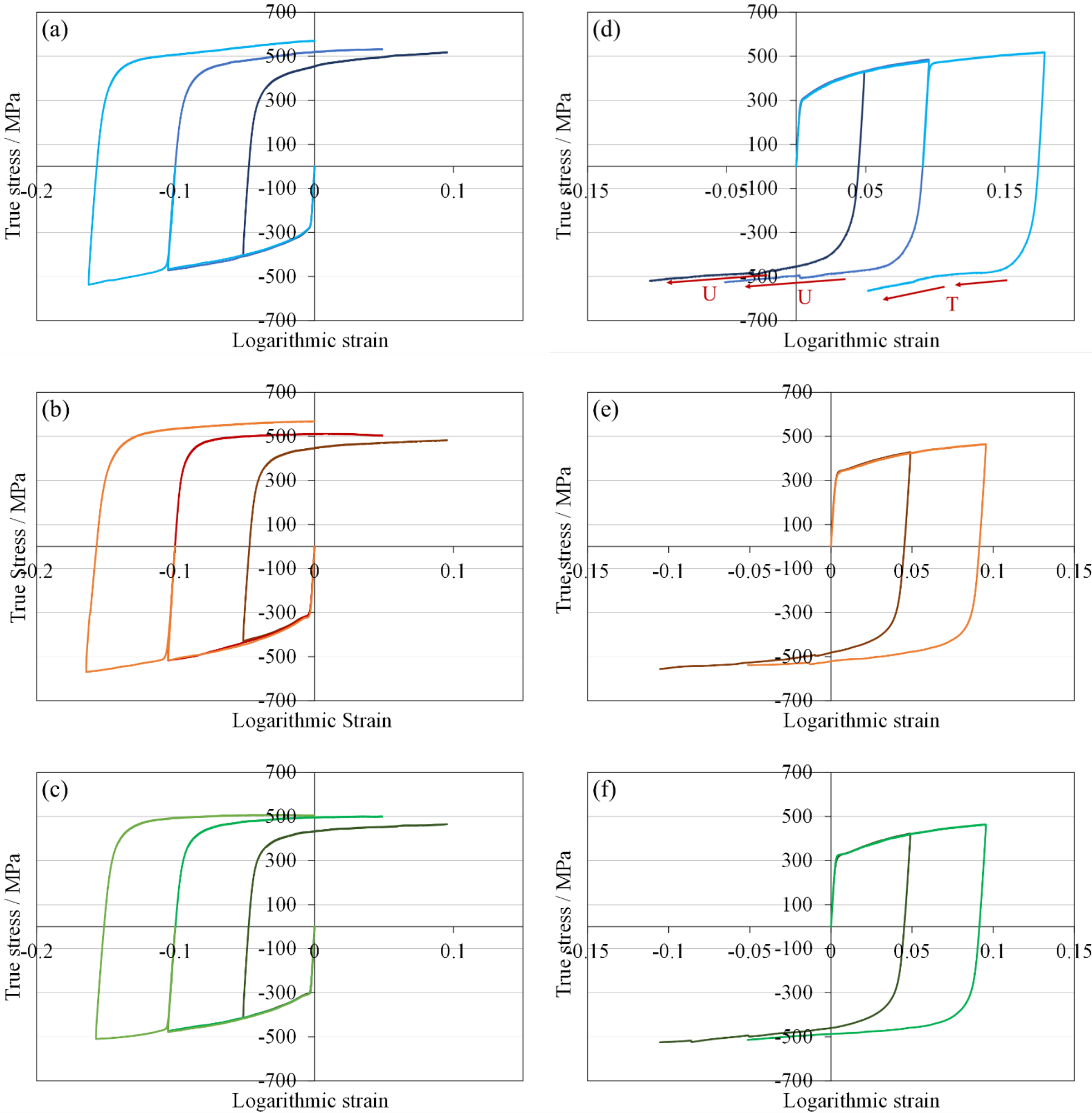

Fig. 6 True stress-logarithmic strain curves obtained under reverse loading in the Grade 2 sheet. (a) CT in RD sample, (b) CT in TD sample, (c) CT in $45^{\circ}$ sample, (d) TC in RD sample, (e) TC in TD sample, and (f) TC in $45^{\circ}$ sample.

In both $\mathrm{CT}$ and $\mathrm{TC}$, the $0.2 \%$ proof stress after the strain reversal is much smaller than the flow stress before the strain reversal in both the Grade 1 and Grade 2 sheets, i.e., the Bauschinger effect is exhibited [9]. To investigate the Bauschinger effect in detail, Fig. 7 plots the absolute true stress-accumulated logarithmic strain curves with an absolute pre-strain of 0.1 . To examine the Bauschinger effect quantitatively, the nondimensional stress difference $\Delta \sigma$ is defined in the form

$$
\Delta \sigma=\left(\sigma_{S}-\sigma_{S}^{\prime}\right) / \sigma_{S}
$$


where $\sigma_{S}$ denotes the flow stress before inverting the loading direction and $\sigma_{S}^{\prime}$ denotes the $0.2 \%$ proof stress after the loading direction was inverted. Note that $\sigma_{S}^{\prime}$ was determined from the true stresslogarithmic strain curves. The $\Delta \sigma$ results are presented in Table 2. $\Delta \sigma$ is larger under TC than CT irrespective of the condition. Similarly, $\Delta \sigma$ is larger in the Grade 2 sheet than in the Grade 1 sheet, that is, the Bauschinger effect is more pronounced in the Grade 2 sheet. Comparing the results among the three orientation samples, the RD sample exhibits a larger Bauschinger effect than the other two samples both in the Grade 1 and Grade 2 sheets.

Table 2 Nondimensionalized stress difference $\Delta \sigma$ for various conditions.

\begin{tabular}{ccccc}
\hline & \multicolumn{2}{c}{ Grade 1 } & \multicolumn{2}{c}{ Grade 2 } \\
& CT & TC & CT & TC \\
\hline RD & 0.400 & 0.440 & 0.393 & 0.457 \\
TD & 0.307 & 0.312 & 0.326 & 0.333 \\
$45^{\circ}$ & 0.256 & 0.328 & 0.318 & 0.370 \\
\hline
\end{tabular}
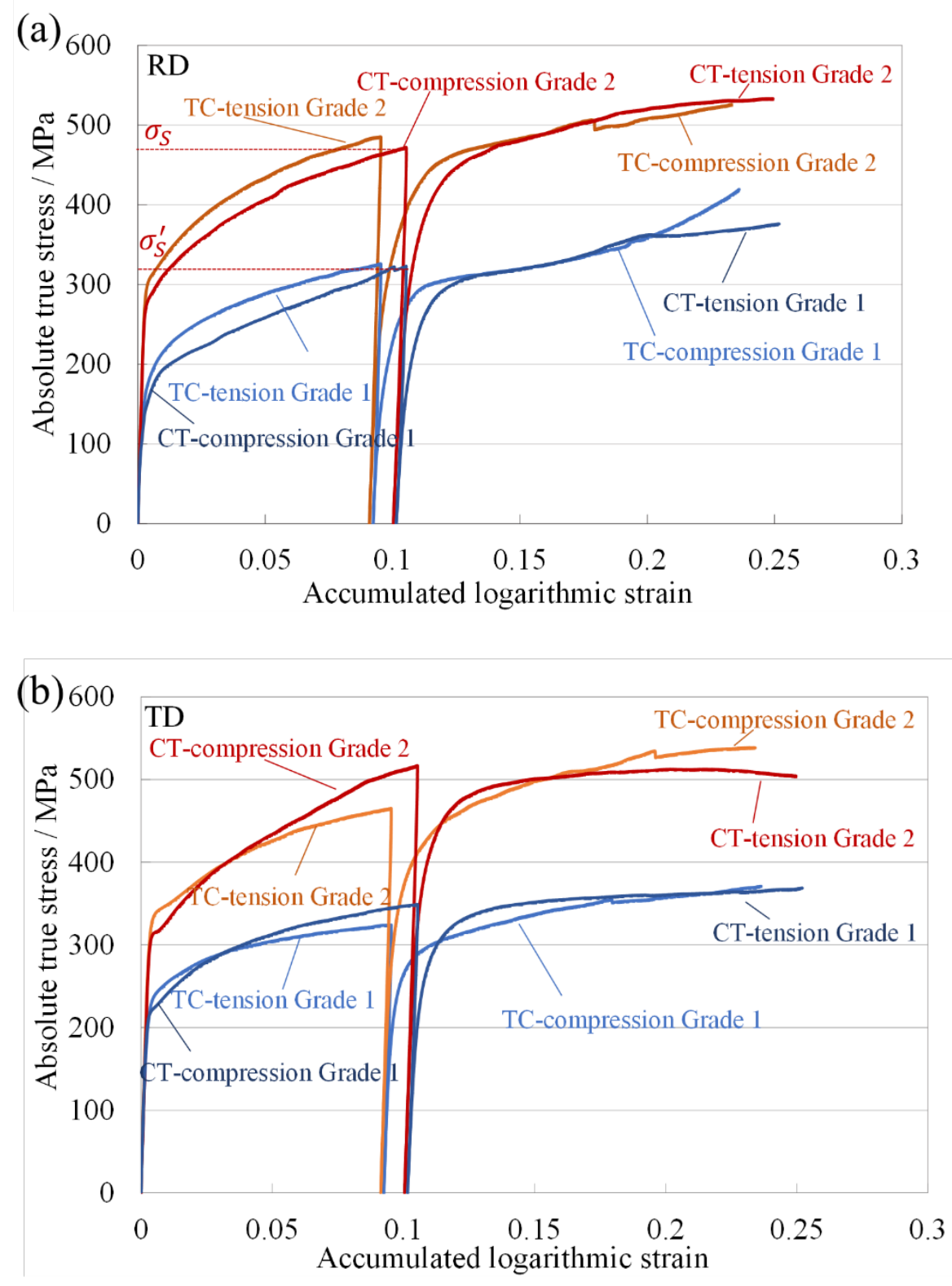


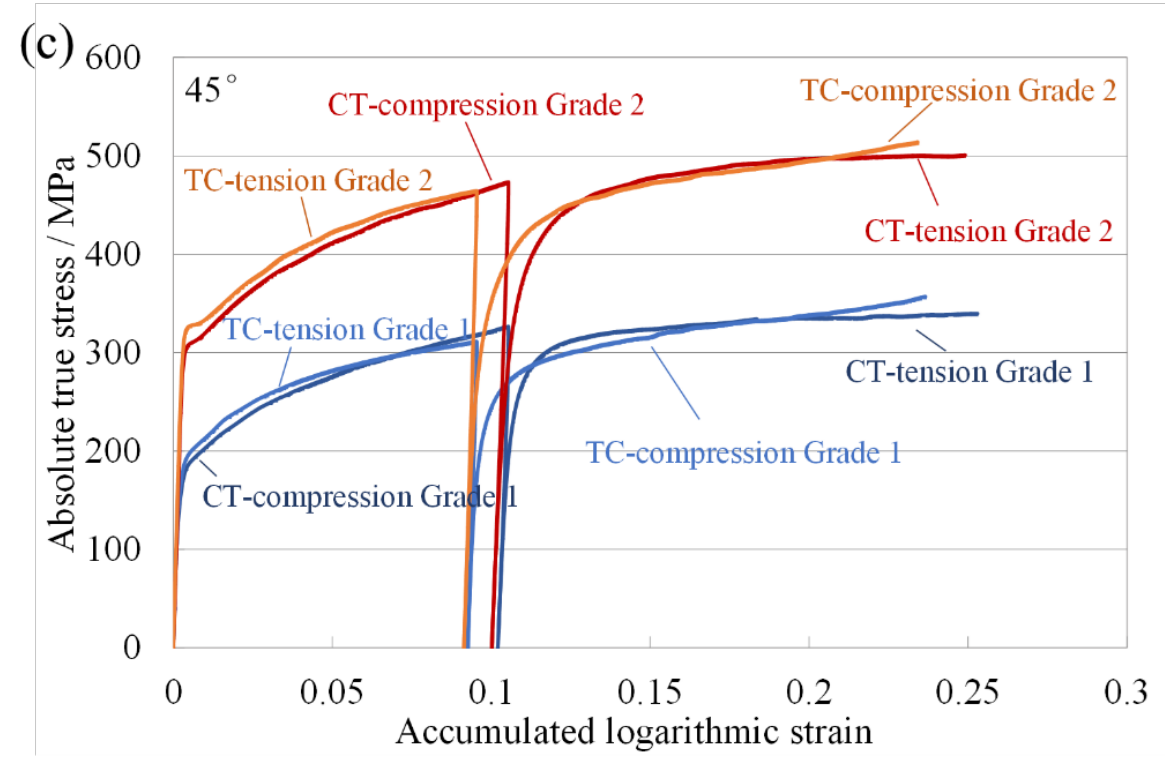

Fig. 7 Absolute true stress-accumulated logarithmic strain curves obtained under TC and CT. A strain of 0.1 was given in the first loading, followed by a strain of 0.15 in the second loading. (a) RD samples, (b) TD samples, and (c) $45^{\circ}$ samples.

\section{Discussion}

\subsection{EBSD measurements}

Twinning activity has been reported in CP-Ti sheets. More specifically, the twinning activity is more pronounced during compression than tension, and detwinning is activated when the sheet is subjected to reverse loading [8-11]. Therefore, the twinning activity is mainly focused on in the present study.

EBSD measurements were conducted for the RD and TD samples of the Grade 1 sheet. Because three twinning systems, i.e., $<10 \overline{1} 2>$, $<11 \overline{2} 1>$ tensile twinning, and $<11 \overline{2} 2>$ compressive twinning systems, were observed in the Grade 2 sheet [9], the same three twinning systems were extracted from IPF maps in the present study. However, it should be noted that among the three twinning systems, $<11 \overline{2} 1>$ tensile twinning was rarely observed in the Grade 1 sheet.

Fig. 8 presents the initial PFs and IPF map. Note that all the PFs and IPF maps displayed in the present paper refer to the color bars shown in Fig. 8. In the initial sample, the typical strong basal texture [7-8, 10-11, 38-39] is observed, and twinning is hardly exhibited. Compared with the PFs of the initial sample of the Grade 2 sheet [9], the maximum intensity in the initial sample is larger in the Grade 1 sheet, which indicates that the anisotropy is more pronounced in the Grade 1 sheet. 


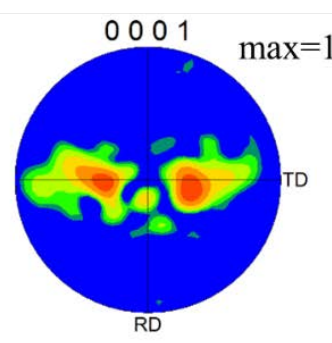

\section{Initial}
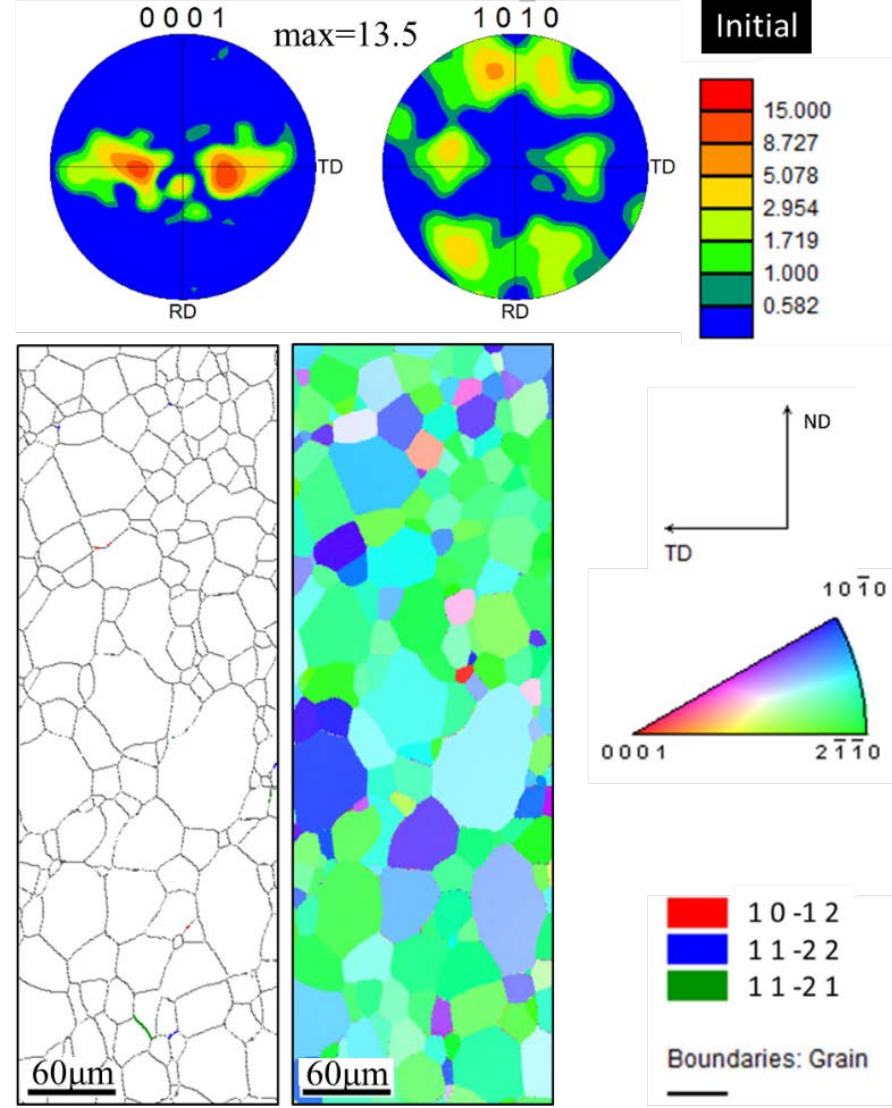

$10-12$

$11-22$

$11-21$

Fig. 8 (0001) and (10̄̄0) PFs and IPF map for initial sample.

The PFs, IPF maps, and extracted grain and twin boundaries obtained under monotonic tension and compression are presented in Fig. 9. The observed points are points A, F, G, and I displayed in Figs. 4 (a) and 4 (b). Under compression, the strong peaks appeared in the RD in the PF after a compressive strain of 0.1 was applied (Fig. 9 (a)). These strong peaks result from the activity of $<10 \overline{1} 2>$ twinning, as observed in the IPF map. The $<10 \overline{1} 2>$ twinning further increased as the compressive strain increased (Fig. 9 (b)). Under tension, $<11 \overline{2} 2>$ twinning was active and further increased upon increasing the tensile strain (Figs. 9 (c) and 9 (d)). However, the PFs remained almost unchanged from those of the initial sample (Fig. 8). The abovementioned results indicate that the type of active twin mode is different between tension and compression. Moreover, the activity of $<10 \overline{1} 2>$ twinning under compression is larger than that of $<11 \overline{2} 2>$ twinning under tension, suggesting that $<10 \overline{1} 2>$ twinning would be more easily activated than $<11 \overline{2} 2>$ twinning. 

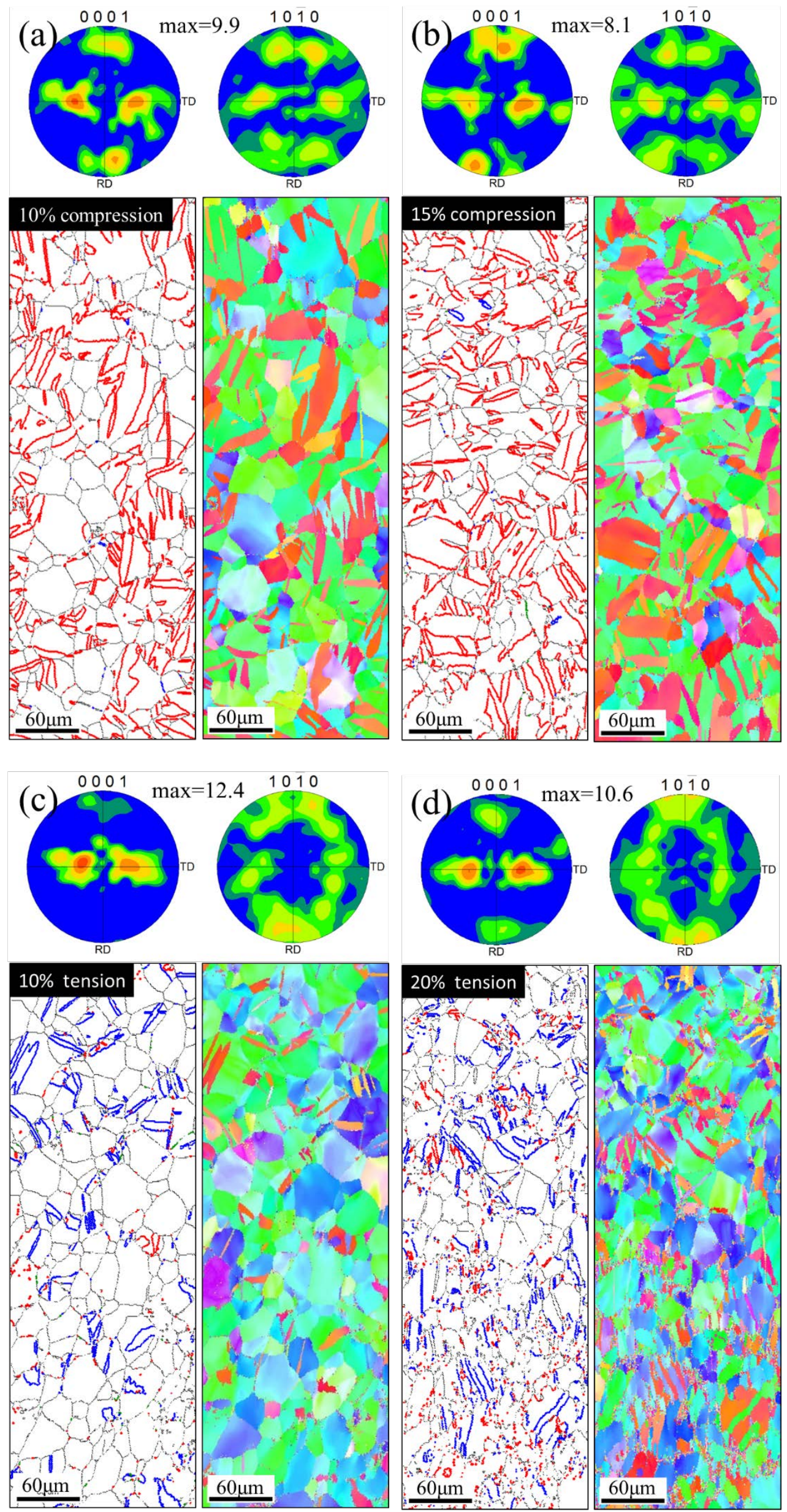

Fig. 9 (0001) and (1010) PFs, IPF maps, and extracted grain boundaries obtained under monotonic loading for RD samples. Results are at (a) point A, (b) point F, (c) point G, and (d) point I shown in Figs. 4 (a) and (b). 
Next, the results obtained under reverse loadings are discussed. Fig. 10 presents the PFs, IPF maps, and extracted grain and twin boundaries obtained during tension under CT (10\% compression followed by $20 \%$ tension) in the RD sample. The observed points are points B, C, and D displayed in Fig. 4 (a). When a tensile strain of 0.05 was applied after the strain reversal (Fig. 10 (a)), the strong peaks in the RD that arose before inverting the loading direction (Fig. 9 (a)) disappeared mostly in the PF, indicating that $<10 \overline{1} 2>$ detwinning was active during tension as observed in the IPF map. The peaks in the RD disappeared completely at a tensile strain of 0.1 in the PF (Fig. 10 (b)), consistent with the fact that $<10 \overline{1} 2>$ detwinning was completed in the IPF map (Fig. 10 (b)). Alternatively, $\langle 11 \overline{2} 2\rangle$ twinning started activating and became more pronounced with the increase in tensile strain, as observed in Figs. 10 (a), 10 (b), and 10 (c), leading to strong peaks in the RD again in the PF (Fig. 10 (c)). This tendency of $<11 \overline{2} 2>$ twinning activity is the same as that observed during monotonic tension (Fig. 9).
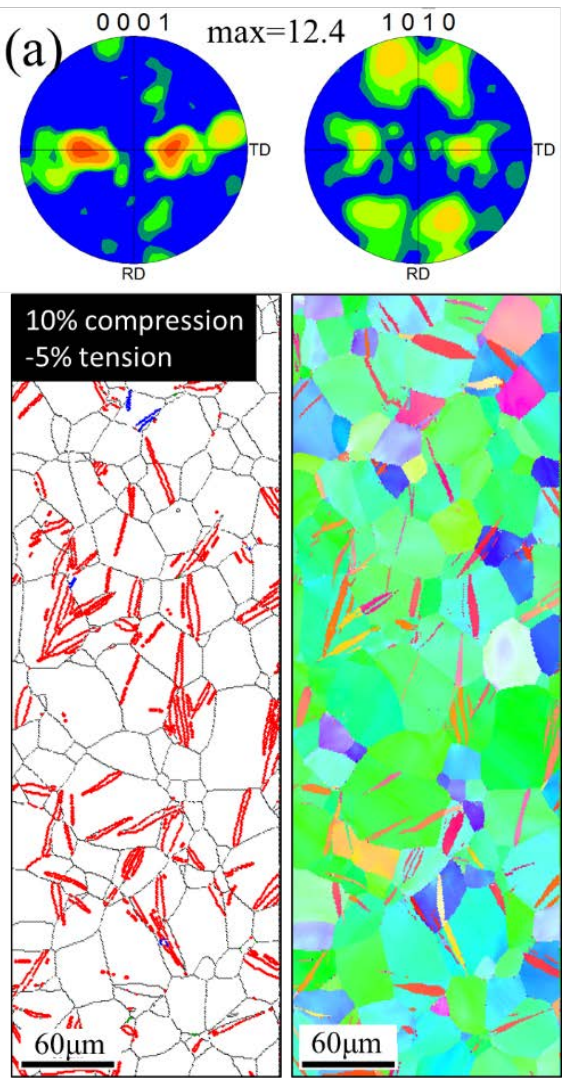
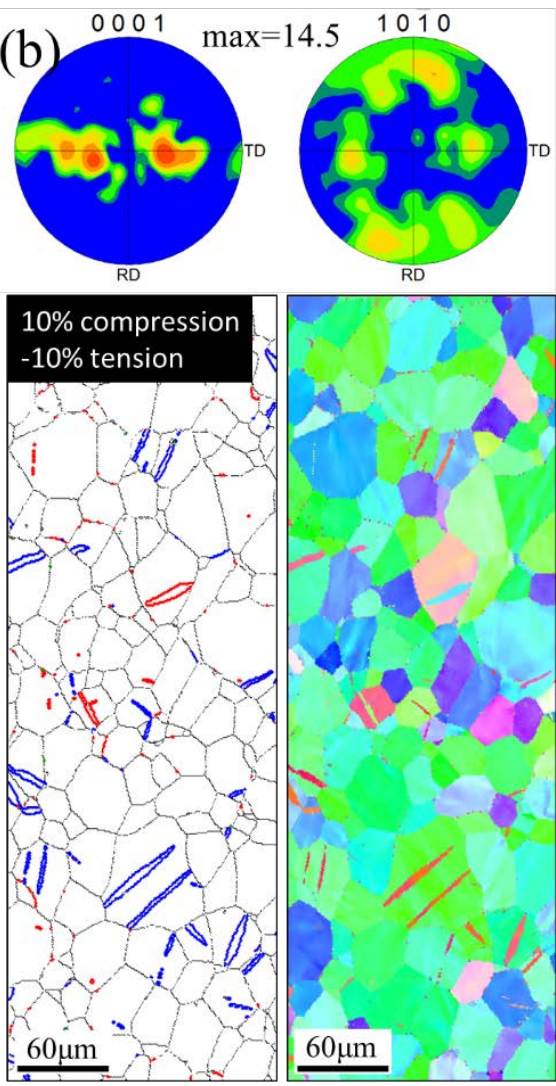
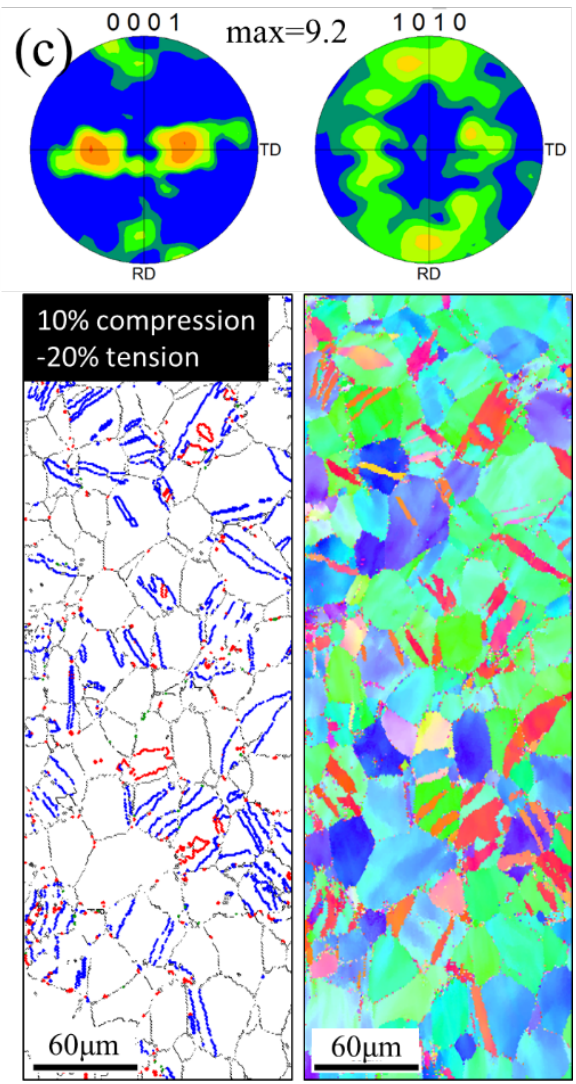

Fig. 10 (0001) and (1010) PFs, IPF maps, and extracted grain boundaries obtained under CT for RD samples. Results are at (a) point B, (b) point C, and (c) point D shown in Fig. 4 (a).

Fig. 11 presents the PFs, IPF maps, and extracted grain and twin boundaries obtained during compression under TC (10\% tension followed by $15 \%$ compression) in the RD samples. The observed point was point $\mathrm{H}$ in Fig. 6 (a). Most of the $<11 \overline{2} 2>$ twinning that was observed before inverting the loading direction (Fig. 9 (c)) disappeared, while $<10 \overline{1} 2>$ twinning occurred, resulting in the strong peaks in the RD as observed in the PF. 

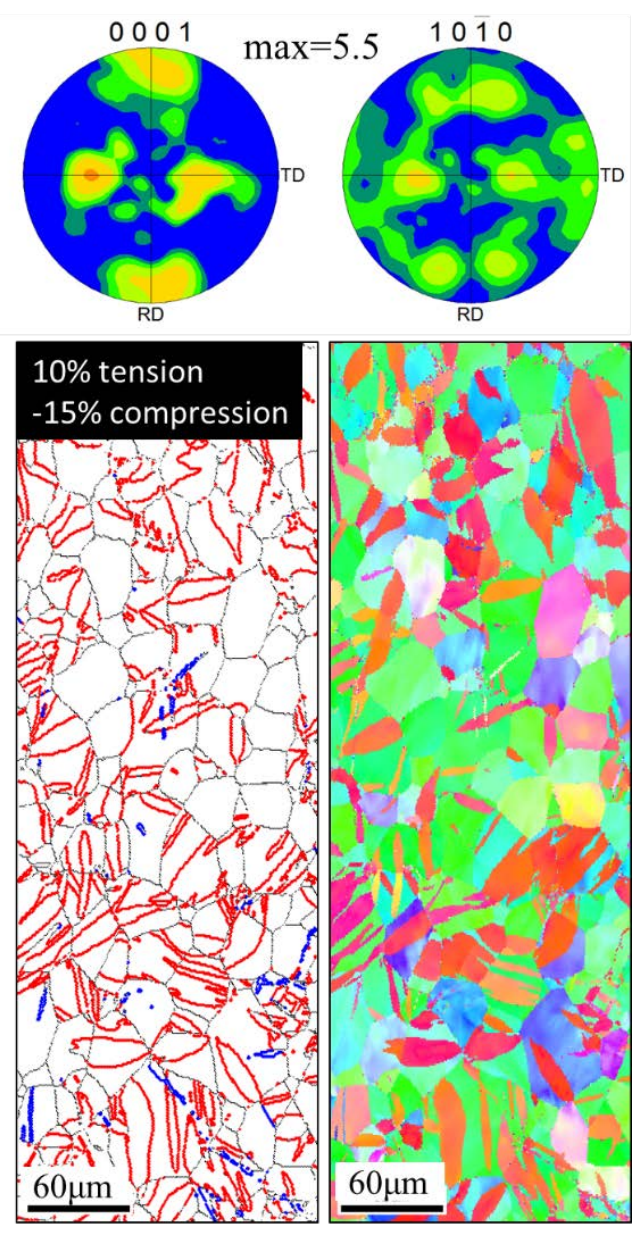

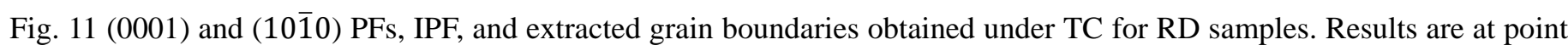
H shown in Fig. 6 (a).

The effect of pre-strain on the subsequent twinning activity is discussed based on the abovementioned results under reverse loadings. Comparing the IPF maps at a tensile strain of 0.1 with and without a compressive pre-strain of 0.1 (Fig. 10 (b) and Fig. 9 (c), respectively), $<11 \overline{2} 2>$ twinning appears to be more activated in the sample without a compressive pre-strain. This difference in $<11 \overline{2} 2>$ twinning activity may results from the activity of $<10 \overline{1} 2>$ detwinning being more pronounced than that of $<11 \overline{2} 2>$ twinning in the initial stage of tension in the sample with a compressive strain. However, the activity of $<11 \overline{2} 2>$ twinning at a tensile strain of 0.2 appears to be similar with and without a compressive pre-strain of 0.1 (Fig. 10 (c) and Fig. 9 (d)). The above comparisons indicate that the pre-straining would affect the subsequent twinning activity in the initial stage to a small extent, and the effect becomes small as the strain increases.

To investigate the in-plane anisotropy of the twinning activity, EBSD measurements were also conducted for the TD samples. The results obtained during monotonic tension and compression are presented in Fig. 12. It is apparent that the twinning activity is much less in the TD sample than in the RD sample. However, the type of activated twin mode is different between the RD and TD samples: $<10 \overline{1} 2>$ twinning was activated in the RD sample, whereas $\langle 11 \overline{2} 2>$ twinning was activated in the TD sample under compression. Similarly, under tension, $<11 \overline{2} 2>$ twinning was activated in the RD sample, whereas $<10 \overline{1} 2>$ twinning was activated in the TD sample. It is presumed that this difference in the active twin mode between the RD and TD samples may result from the difference in the initial texture between the RD and TD. 

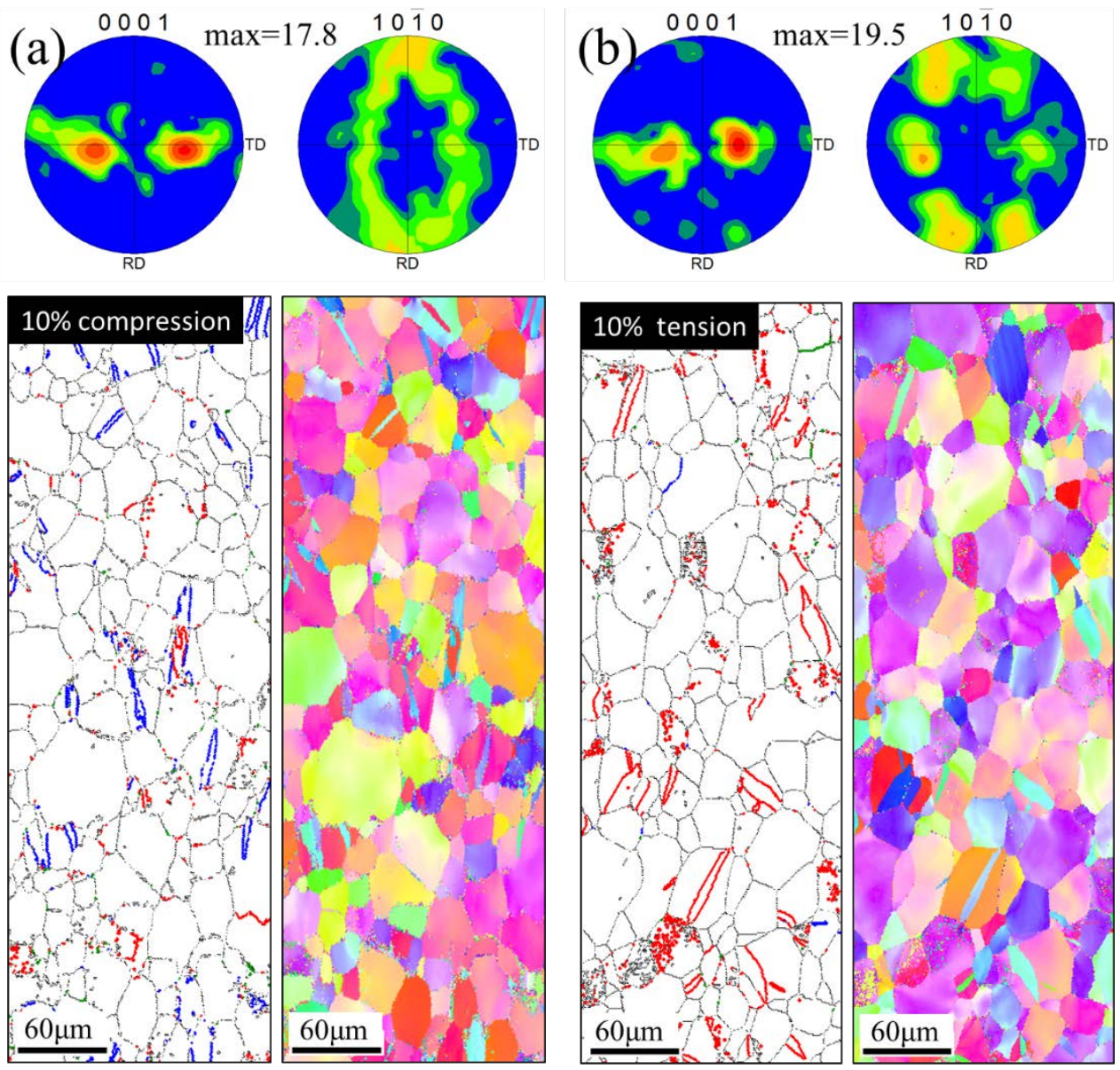

Fig. 12 (0001) and (1010) PFs, IPF, and extracted grain boundaries obtained under monotonic loadings for TD samples. Results are at (a) point J and (b) point K shown in Figs. 4 (b) and 4 (e).

Finally, the twinning activities are compared between the Grade 1 and Grade 2 sheets. The tendencies of the abovementioned texture evolution observed in the RD samples of the Grade 1 sheet are qualitatively the same as those of the Grade 2 sheet [9], i.e., $<10 \overline{1} 2>$ twinning and $<11 \overline{2} 2>$ twinning are active during compression and tension, respectively, and $\langle 10 \overline{1} 2>$ detwinning is observed when the loading direction is inverted from compression to tension. Note that because EBSD measurements were not performed under TC in our previous study, in the present study, we observed for the first time $<11 \overline{2} 2\rangle$ detwinning when the loading direction was inverted from tension to compression. Moreover, although several twin modes have been reported in CP-Ti [8, 10-11, 15-16], the activities of $<10 \overline{1} 2>$ and $\langle 11 \overline{2} 2>$ twinning are dominant in both Grade 1 and Grade 2 sheets. However, from a quantitative viewpoint, the twinning activity was much more pronounced in the Grade 1 sheet than in the Grade 2 sheet, and this tendency holds for both $<10 \overline{1} 2>$ and $<11 \overline{2} 2>$ twinning.

\subsection{Effect of twinning activity on mechanical behavior}

The stress-strain curves of Mg alloy sheets are significantly different between tension and compression [21, 31, 40-42]. Moreover, a sigmoidal curve occurs when a Mg alloy sheet is subjected to compression followed by tension, whereas this curve does not occur under tension followed by compression [20, 21, 41]. The abovementioned asymmetric work-hardening behaviors arise because of the activities of $<10 \overline{1} 2>$ twinning and detwinning [20, 40-42]. Clearly, the twinning activity plays an important role in the stressstrain curves in Mg alloy sheets. However, as reported in our previous paper [9], the degree of asymmetry in 
the work-hardening behavior was much less pronounced in the CP-Ti Grade 2 sheet even though $<10 \overline{1} 2>$ twinning and detwinning were activated. It was presumed in the previous paper that one of the reasons for this difference between the Mg alloy and CP-Ti Grade 2 sheets was that the activities of twinning and detwinning were much smaller in the CP-Ti Grade 2 sheet than in the Mg alloy sheet. If this presumption is correct, the CP-Ti Grade 1 sheet would exhibit a stronger asymmetry in stress-strain curves than that of the Grade 2 sheet because the twinning activity is much larger in the Grade 1 sheet than in the Grade 2 sheet, as described in the previous section. From this viewpoint, the EBSD measurements described in section 4.1 were used to reexamine the effect of twinning activity on the stress-strain curves in CP-Ti sheets.

For monotonic loading in the RD samples of the Grade 1 sheet, as we discussed in section 3.1, the work-hardening rate was larger under compression than under tension, as observed in Fig. 3 (c). One of the reasons for this result may be explained in terms of twinning activity as follows. As explained in section 4.1, $<10 \overline{1} 2>$ twinning under compression is more active than $<11 \overline{2} 2>$ twinning under tension. Because the increase in twin boundaries would strengthen the work-hardening [43-44], the work-hardening under compression became larger than that of tension. This presumption would be supported by the following results in the Grade 2 sheet: the twinning activity was much smaller than that of the Grade 1 sheet; thus, no obvious difference in the work-hardening rate appeared between tension and compression (Fig. 3 (c)).

Next, the correlation between the stress-strain curve and the twinning activity under CT was investigated. As discussed previously, a small but sharp stress peak (stage Q in Fig. 4 (a)) appeared during tension in the RD sample of the Grade 1 sheet. During the tension, $<10 \overline{1} 2>$ detwinning was activated during the initial stage (Fig. 10 (a)) and then, at the stress peak, $<10 \overline{1} 2>$ detwinning was almost completed, and $<11 \overline{2} 2>$ twinning started activating (Fig. 10 (b)). Thereafter, $<11 \overline{2} 2>$ twinning continued to be activated (Fig. 10 (c)), which is consistent with the tendency observed in monotonic tension (Fig. 9 (c)). These results suggest that the $<10 \overline{1} 2>$ detwinning activity was pronounced before the stress peak occurred, whereas the deformation behavior after the stress peak occurred was similar to that of monotonic tension. Clearly, the deformation behavior near the stress peak observed in the CP-Ti Grade 1 sheet is analogous to the second rapid increase in stress in the sigmoidal curve observed under CT in Mg alloy sheets [42]. Because this stress peak was not observed in the Grade 2 sheet in which the twinning activity was small, this analogy indicates that detwinning activity still affects the stress-strain curve even in a CP-Ti sheet if its activity is large.

However, the difference in the stress before and after the stress peak occurred is clearly much smaller in the CP-Ti Grade 1 sheet than in the Mg alloy sheets. This finding occurred because the difference in CRSSs among the active deformation mechanisms is smaller in the CP-Ti sheet than in the Mg alloy sheets [45-46]. From the abovementioned results and discussion, we conclude that the effect of twinning activity on the stress-strain curve is essentially much smaller in the CP-Ti sheet than in the Mg alloy sheets.

Finally, the correlation under TC was examined. The stress-strain curves under compression with tensile pre-strains of 0.05 and 0.1 were very similar to those of monotonic compression in the Grade 2 sheet (Fig. 6 (d)). This finding occurred because the activity of $\langle 11 \overline{2} 2\rangle$ twinning during tension was small in the Grade 2 sheet. However, for the tensile pre-strain of 0.2 in the Grade 2 sheet and all the conditions in the Grade 1 sheet, the work-hardening rate increased in the latter stage, and this tendency is different from that of monotonic compression. This result may be related to the activity of $\langle 11 \overline{2} 2\rangle$ detwinning during compression under TC. However, further investigation is required to validate this presumption.

\subsection{Cyclic loading}


Based on the abovementioned results of monotonic and reverse loadings, the stress-strain response under cyclic loading is discussed. The true stress-logarithmic strain curves obtained under cyclic loading with pre-strain $\varepsilon_{0}=-0.03$ and strain amplitude $\varepsilon \mathrm{S}=0.1$ in the RD samples are presented in Fig. 13 . The tests were started with compression. The results up to 4 cycles are presented here. The flow stress increases as the number of cycles increases under both tension and compression in both the Grade 1 and Grade 2 sheets. However, the increase in stress upon increasing the number of cycles is larger in the Grade 1 sheet than the in the Grade 2 sheet.
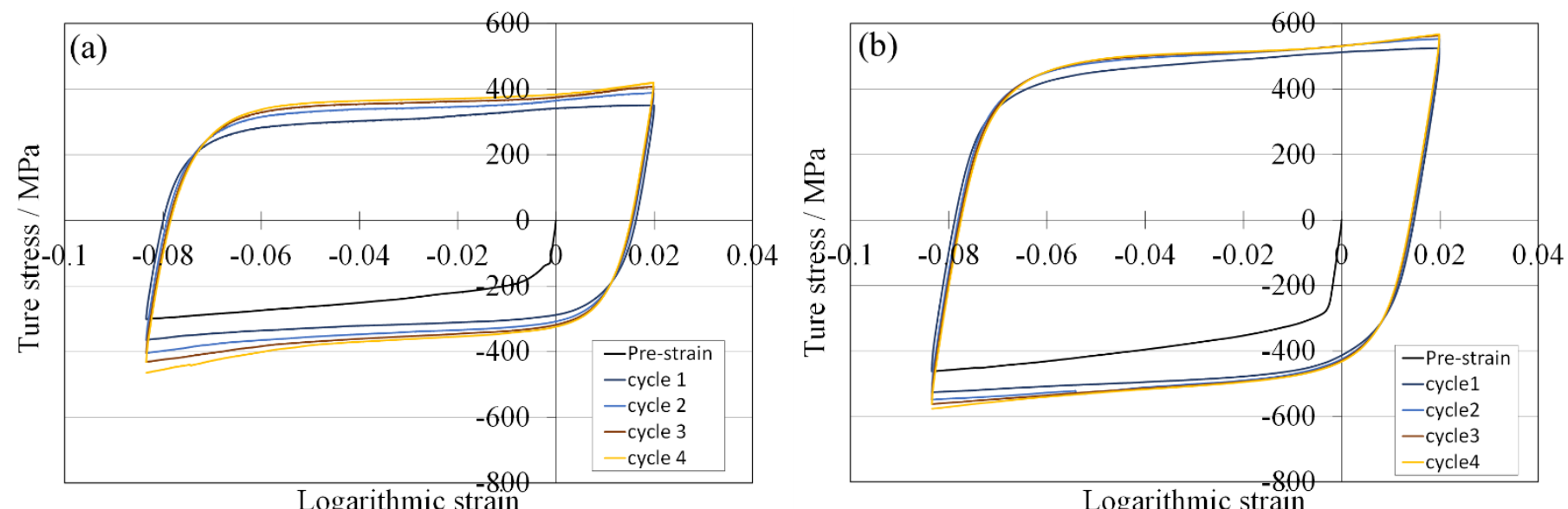

Fig. 13 True stress-logarithmic strain curves obtained under cyclic loading in RD samples of (a) the Grade 1 sheet and (b) the Grade 2 sheet.

To investigate the work-hardening behavior in each cycle, the stress-strain curves were separated into single cycles, as shown in Fig. 14. Interestingly, the small but sharp stress peak that appeared during tension following compression at the 1st cycle in the Grade 1 sheet was not observed in the subsequent cycles. This mechanism may be explained in terms of an analogy with Mg alloy sheets as follows. It was reported that in a Mg alloy sheet, a retardation of the beginning of the second rapid increase in work-hardening, i.e., the expansion of plateau region, was observed during compression in cyclic loading [21, 35]. This work-hardening behavior occurred for the following reason. Although detwinning was active during tension in cyclic loading, some twinned regions remained even at the end of tension; thus, the area fractions of twins at the end of tension and compression increased as the number of cycles increased. Because of the increase in the area fraction at the beginning of tension, the strain range where detwinning could be activated expanded, i.e., the plateau region expanded, and the beginning of the second rapid increase in stress was retarded. It is presumed that this mechanism is also applicable to the CP-Ti sheet, i.e., the occurrence of a stress peak during tension would be retarded as the number of cycles increases. If this presumption is correct, a stress peak would arise when the sheet is subjected to cyclic loading followed by tension. To validate this presumption, the stress-strain curve obtained under two cyclic loadings followed by tension in the Grade 1 sheet is displayed in Fig. 15. As expected, a stress peak does not appear during the 2nd cycle but appears during the subsequent tension. Clearly, the occurrence of a stress peak is retarded when a sheet is subjected to cyclic loading. Based on this result, we conclude that the activities of twinning and detwinning affect the stress-strain curve under cyclic loading in the Grade 1 sheet to a small extent even though the degree of influence is much less than in Mg alloy sheets. 


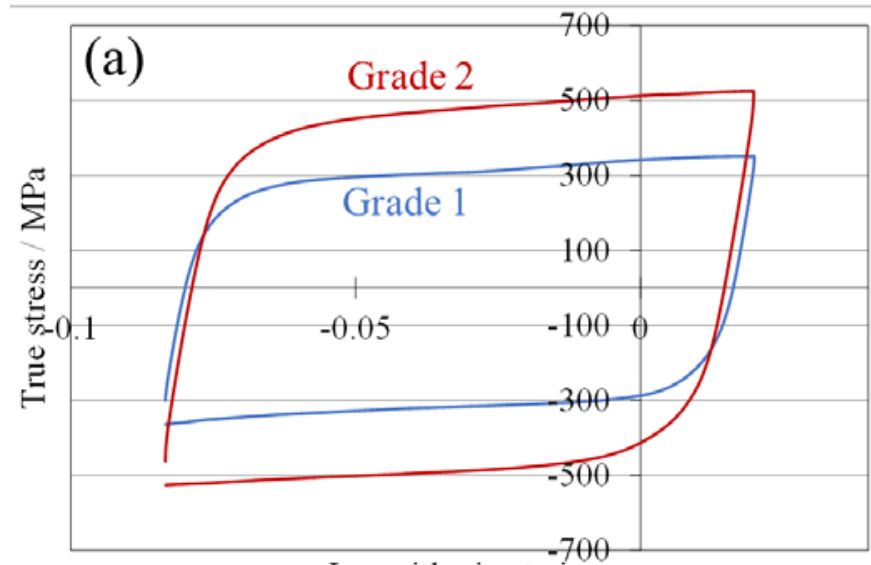

Logarithmic strain

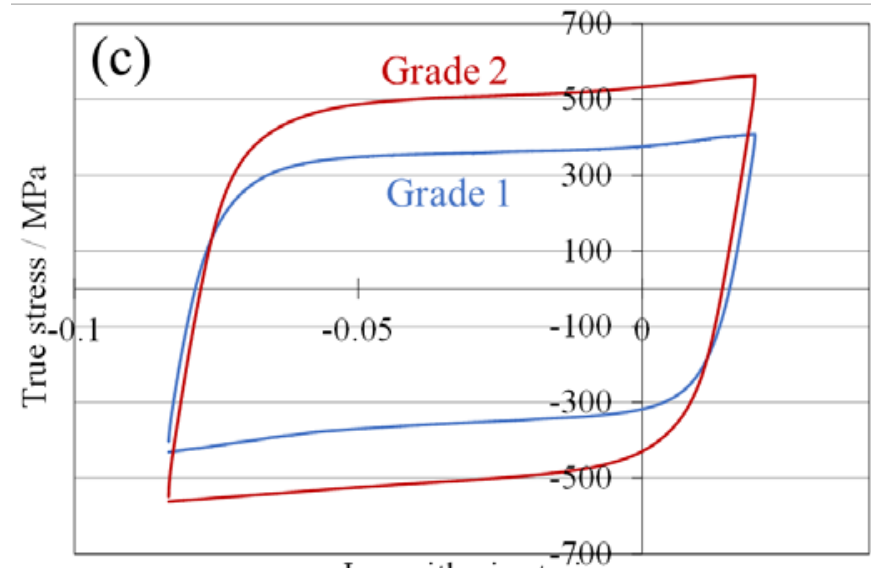

Logarithmic strain

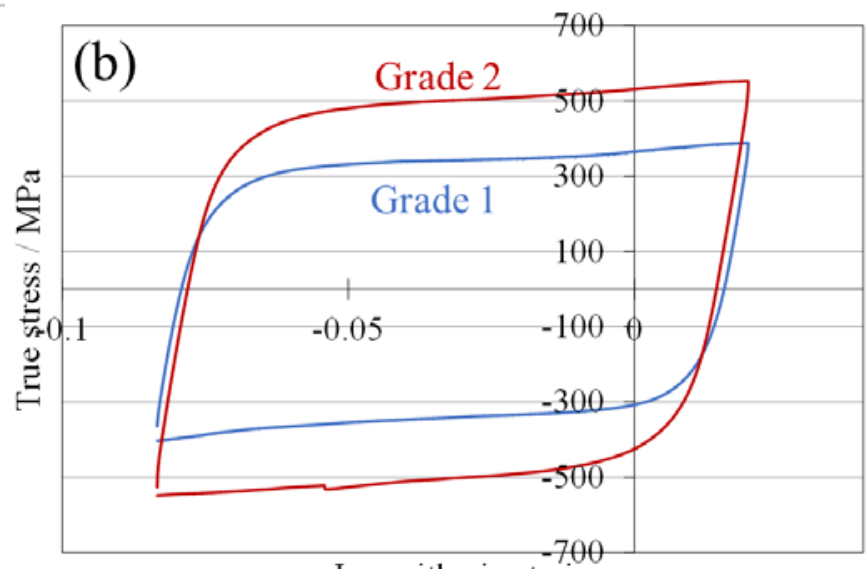

Logarithmic strain

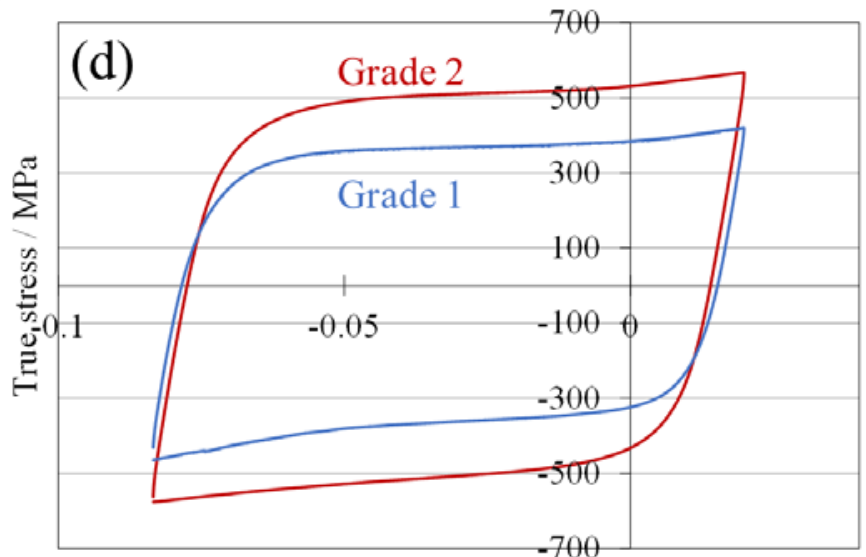

Logarithmic strain

Fig. 14 True stress-logarithmic strain curves of each cycle in Grade 1 and Grade 2 sheets. (a) 1st cycle (b) 2nd cycle (c) 3rd cycle, and (d) 4th cycle.

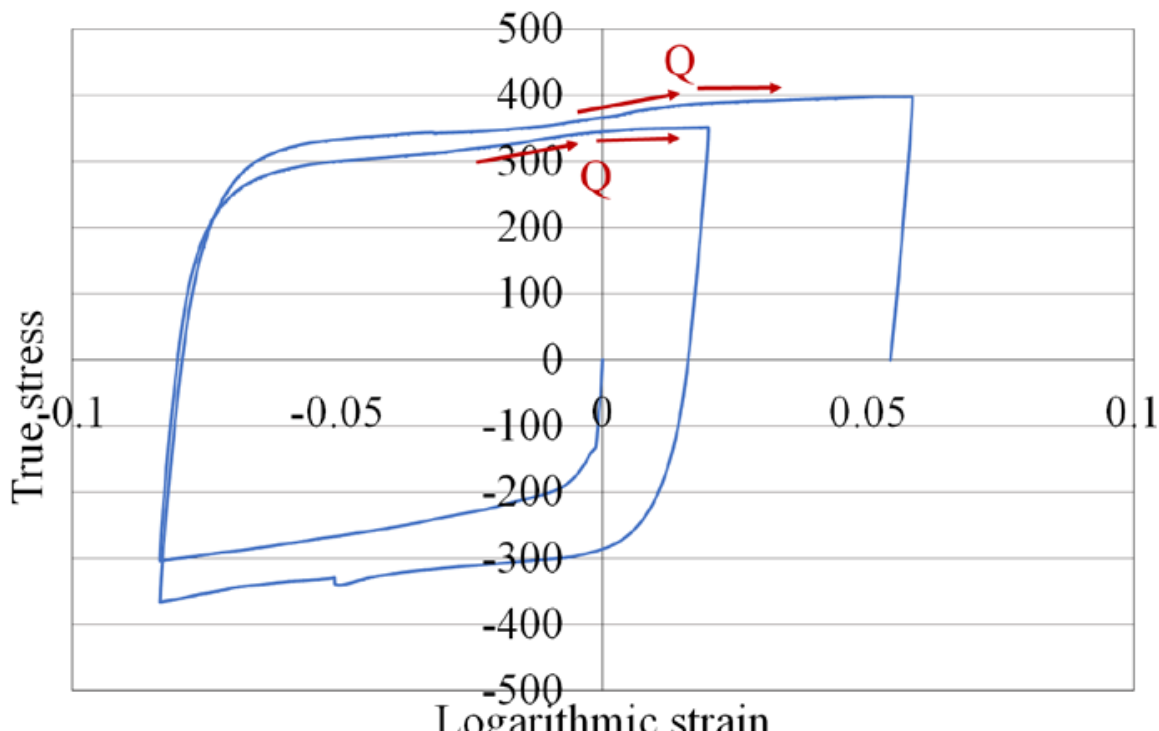

Fig. 15 True stress-logarithmic strain curve obtained under two-cyclic loading followed by tension in RD sample of the Grade 1 sheet.

Next, the effects of $\varepsilon 0$ and $\varepsilon s$ on the stress-strain curve are examined. Fig. 16 presents the stress-strain curves obtained with different $\varepsilon_{0}$ and $\varepsilon s$. For a better comparison, the change in stress at the end of both tension and compression as a function of the number of cycles is depicted in Fig. 17. 

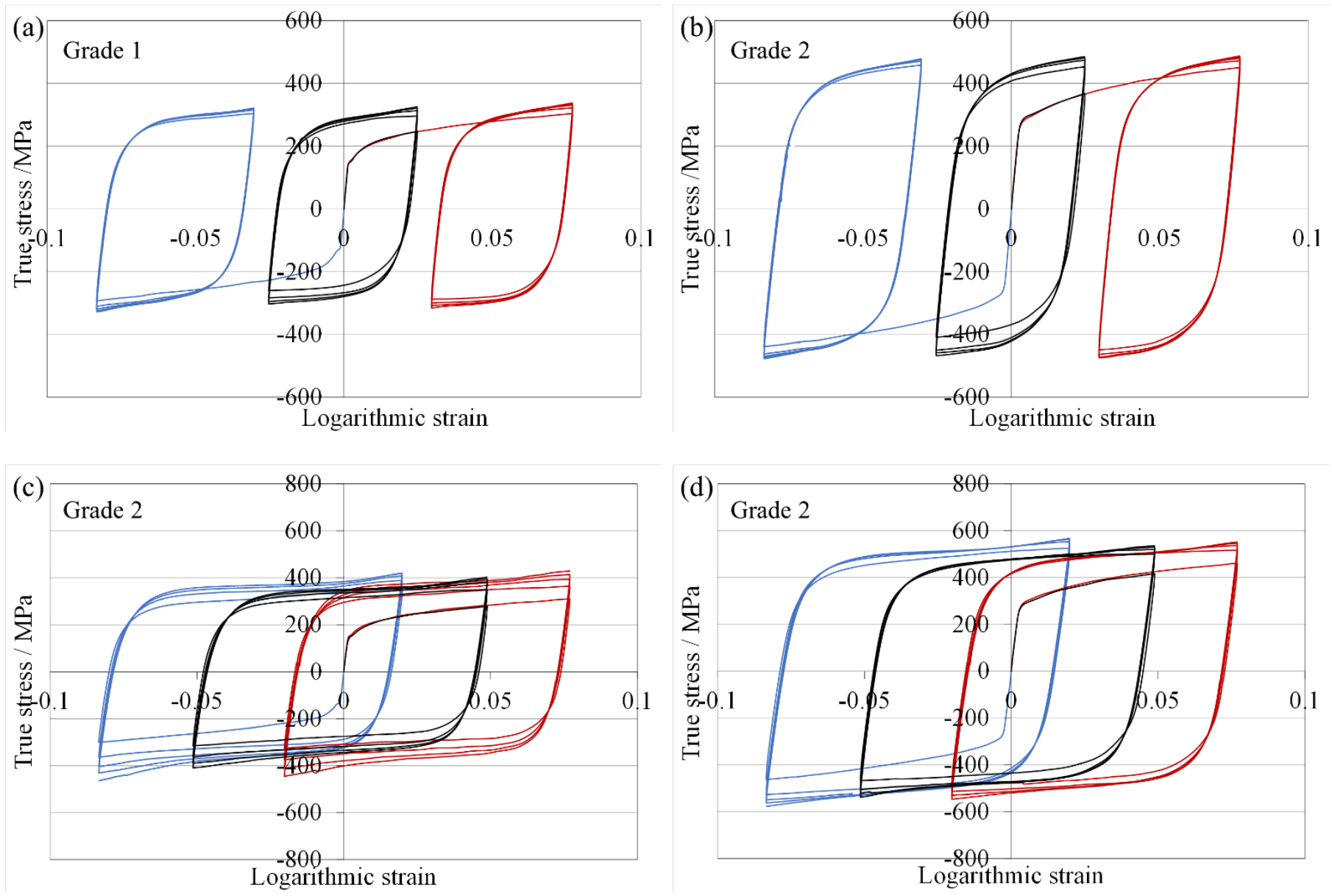

Fig. 16 True stress-logarithmic strain curves obtained under cyclic loading with different $\varepsilon 0$ and $\varepsilon \mathrm{s}$. (a) $\varepsilon_{\mathrm{S}}=0.05$ and $\varepsilon_{0}=$ 0.055, 0 , and -0.055 in the Grade 1 sheet, (b) $\varepsilon_{\mathrm{S}}=0.05$ and $\varepsilon_{0}=0.055,0$, and -0.055 in the Grade 2 sheet, (c) $\varepsilon_{\mathrm{S}}=0.1$ and $\varepsilon_{0}$ $=0.3,0$, and -0.03 in the Grade 1 sheet, and (d) $\varepsilon_{\mathrm{S}}=0.1$ and $\varepsilon_{0}=0.3,0$, and -0.03 in the Grade 2 sheet.

The stress increases as the number of cycles increases in both tension and compression for both Grade 1 and Grade 2 sheets regardless of $\varepsilon_{0}$ and $\varepsilon$ s. More specifically, the stress at the end of tension increases gradually as the number of cycles increases under all conditions (Figs. 17 (a) and 17 (c)). This tendency is more pronounced in the Grade 2 sheet than in the Grade 1 sheet. Under compression (Figs. 17 (b) and 17 (d)), the stress increases almost linearly as the number of cycles increases.

Concerning the effect of $\varepsilon$ s, the stress increase with increasing number of cycles is apparently larger for $\varepsilon \mathrm{s}=0.1$ than $\varepsilon \mathrm{s}=0.05$. This tendency is the same regardless of $\varepsilon 0$ in both the Grade 1 and Grade 2 sheets. Similar performance was observed in a CP-Ti sheet under cyclic fatigue tests $[12,19]$. For the effect of $\varepsilon_{0}$, the stresses are the smallest for $\varepsilon 0=0$ under both tension and compression regardless of $\varepsilon \mathrm{s}$ in both Grade 1 and Grade 2 sheets. This trend arises because the work-hardening during pre-straining is the smallest.

Comparing the results of cyclic loading in a Mg alloy sheet [21], $\varepsilon 0$ and $\varepsilon s$ have less effect on the stressstrain curve on the $\mathrm{CP}-\mathrm{Ti}$ sheets than the $\mathrm{Mg}$ alloy sheet, which is also related to the smaller twinning activities in the CP-Ti sheets than the Mg alloy sheet, as we discussed previously. 


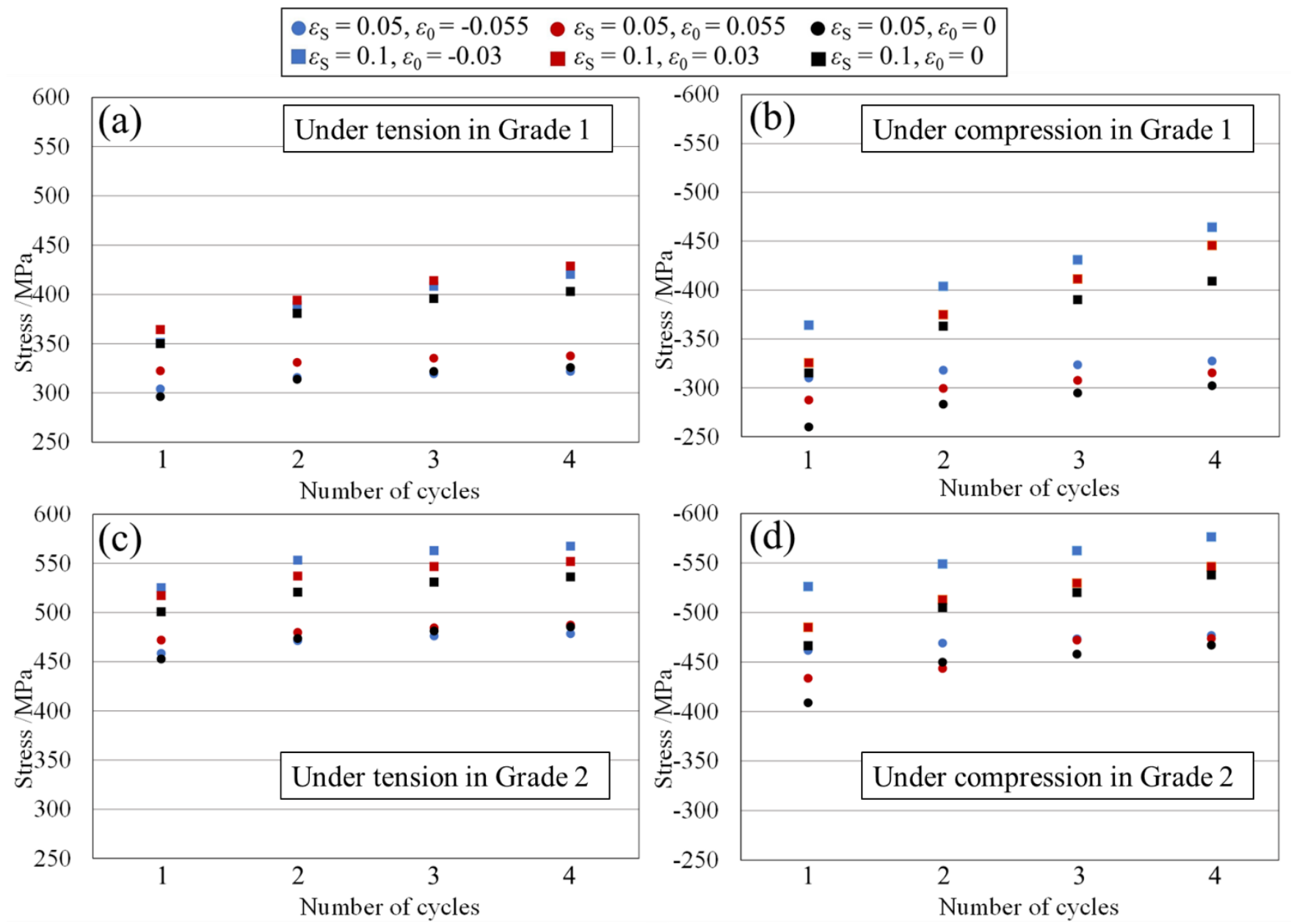

Fig. 17 Changes in stress at the end of tension and compression as a function of number of cycles. (a) Under tension in Grade 1 sheet, (b) under compression in Grade 1 sheet, (c) under tension in Grade 2 sheet, and (d) under compression in Grade 2 sheet.

\section{Conclusions}

The present study investigated the anisotropy in the mechanical behavior in CP-Ti Grade 1 and Grade 2 sheets under monotonic, reverse, and cyclic loading. The mechanical tests were conducted using samples prepared along the $\mathrm{RD}$, the $\mathrm{TD}$, and $45^{\circ}$ from the $\mathrm{RD}\left(45^{\circ}\right.$ sample). EBSD measurements were also used to examine the twinning activity. Furthermore, the effect of twinning activity on the stress-strain response was studied by reference to the case of Mg alloy sheets. The results obtained were as follows:

1. Under monotonic tension, the CP-Ti Grade 2 sheet exhibits larger strength and smaller elongation than the Grade 1 sheet. For both the Grade 1 and Grade 2 sheets, the TD sample exhibits the largest yield strength, the RD sample exhibits the largest tensile strength, and the $45^{\circ}$ sample exhibits the largest total elongation. The anisotropy in mechanical properties is more pronounced in the Grade 1 sheet than in the Grade 2 sheet.

2. In the RD sample of the Grade 1 sheet, a small but sharp stress peak arises during tension under CT regardless of the pre-strain. This tendency does not occur in the Grade 2 sheet. Under TC, two work-hardening stages appear during compression regardless of the pre-strain. This tendency occurs in the Grade 1 sheet irrespective of the condition, whereas it occurs in the Grade 2 sheet only when the pre-strain is large. In the TD and $45^{\circ}$ samples, the above trends do not occur in either the Grade 1 or Grade 2 sheets.

3. In the RD samples of both Grade 1 and Grade 2 sheets, $<10 \overline{1} 2>$ twinning and detwinning are active, respectively, during compression and tension under CT. Similarly, $<11 \overline{2} 2>$ twinning and detwinning are 
active during tension and compression under TC. In the TD samples of the Grade 1 sheet, in contrast, $<10 \overline{1} 2>$ twinning and $<11 \overline{2} 2>$ twinning are active, respectively, during tension and compression. The twinning activity is much more pronounced in the Grade 1 sheet than in the Grade 2 sheet for both $<10 \overline{1} 2>$ and $<1 \overline{2} 2>$ twinning.

4. Near the stress peak observed during tension under CT in the RD sample of the Grade 1 sheet, $<10 \overline{1} 2>$ detwinning is almost completed, and $<11 \overline{2} 2>$ twinning starts activating. Thereafter, $<11 \overline{2} 2>$ twinning continues to be activated, which is consistent with the tendency observed in monotonic tension. This result suggests that the stress peak occurs because of the twinning and detwinning activities, and this tendency is analogous to the second rapid increase in stress in the sigmoidal curve observed under CT in Mg alloy sheets. However, the effect of twinning activity on the stress-strain curves is essentially much smaller in the CP-Ti sheet than in the Mg alloy sheets. A stress peak arises only in the Grade 1 sheet because the twinning activity is much smaller in the Grade 2 sheet.

5. The occurrence of a stress peak is retarded when the sheet is subjected to cyclic loading for the Grade 1 sheet because, as for $\mathrm{Mg}$ alloy sheets, the volume fraction of twins increases with increasing number of cycles. The stress increase with the increasing of the number of cycles is apparently larger for $\varepsilon s=0.1$ than $\varepsilon \mathrm{s}=0.05$ regardless of $\varepsilon 0$, and the stresses for $\varepsilon_{0}=0$ are the smallest regardless of $\varepsilon \mathrm{s}$ for both Grade 1 and Grade 2 sheets. The stress increase is more pronounced in the Grade 1 sheet under all the conditions. However, $\varepsilon_{0}$ and $\varepsilon$ s have less effect on the stress-strain curves for the CP-Ti sheets than for the Mg alloy sheets.

\section{Acknowledgements}

The authors wish to acknowledge Dr. Tsutomu Tanaka and Mr. Sohei Uchida of Technology Research Institute of Osaka Prefecture for their help with the EBSD measurement. This work was partially supported by JSPS KAKENHI Grant Number 26289271 and the Photon and Quantum Basic Research Coordinated Development Program from the Ministry of Education, Culture, Sports, Science and Technology, Japan.

\section{References}

[1] H Fujii, K Takahashi, Y Yamashita. Application of titanium and its alloys for automobile parts. Nippon Steel Tech. Rep. (2003): 62-67.

[2] F.H. Froes, H. Friedrich, J. Kiese, D. Bergoint. Titanium in the family automobile: the cost challenge. Jom 56.2 (2004): 40-44.

[3] R. Thomas. Titanium in the geothermal industry. Geothermics 32.4 (2003): 679-687.

[4] P.G. Partridge. The crystallography and deformation modes of hexagonal close-packed metals. Metall. rev. 12.1 (1967): 169-194.

[5] J.W. Christian, S. Mahajan. Deformation twinning. Prog. Mater Sci. 39.1 (1995): 1-157.

[6] M. H. Yoo. Slip, twinning, and fracture in hexagonal close-packed metals. Metall. Trans. A 12.3 (1981): 409-418.

[7] X. G. Deng, S. X. Hui, W. J. Ye, X. Y. Song. Analysis of twinning behavior of pure Ti compressed at different strain rates by Schmid Factor. Mater. Sci. Eng. A 575 (2013): 15-20.

[8] M. Tritschler, A. Butz, D. Helm, G. Falkinger, J. Kiese. Experimental analysis and modeling of the anisotropic response of titanium alloy $\mathrm{Ti}-\mathrm{X}$ for quasi-static loading at room temperature. Inter. J. Mater. Form. 7.3 (2014): 259-273.

[9] T. Hama, H. Nagao, A. Kobuki, H. Fujimoto, H. Takuda. Work-hardening and twinning behaviors in a 
commercially pure titanium sheet under various loading paths. Mater. Sci. Eng. A 620 (2015): 390-398.

[10] N. Bozzolo, L. Chan, A. D. Rollett. J. Misorientations induced by deformation twinning in Titanium. Appl. Crystallogr. 43.3 (2010): 596-602.

[11] W. Tirry, S. Bouvier, N. Benmhenni, W. Hammami, A. M. Habraken, F. Coghe, D. Schryvers, L. Rabet. Twinning in pure Ti subjected to monotonic simple shear deformation. Mater. Charact. 72(2012)24-36.

[12] Q.Y. Sun, H.C. Gu. Tensile and low-cycle fatigue behavior of commercially pure titanium and Ti-5Al2.5Sn alloy at 293 and 77 K. Mater. Sci. Eng. A 316.1 (2001): 80-86.

[13] N.P. Gurao, Rajeev Kapoor, Satyam Suwas. Deformation behaviour of commercially pure titanium at extreme strain rates. Acta Mater. 59.9 (2011): 3431-3446.

[14] A. A. Salem, S. R. Kalidindi, R. D. Doherty. Strain hardening of titanium: role of deformation twinning. Acta Mater. 51.14 (2003): 4225-4237.

[15] S Nemat-Nasser, WG Guo, JY Cheng. Mechanical properties and deformation mechanisms of a commercially pure titanium. Acta Mater. 47.13 (1999): 3705-3720.

[16] D. R. Chichili, K. T. Ramesh, K. J. Hemker. The high-strain-rate response of alpha-Titanium: experiments, deformation mechanisms and modeling. Acta Mater. 46.3 (1998): 1025-1043.

[17] D. Jia, Y. M. Wang, K. T. Ramesh, E. Ma, Y. T. Zhu, R. Z. Valiev. Deformation behavior and plastic instabilities of ultrafine-grained titanium. Appl. Phys. Lett. 79.5 (2001): 611-613.

[18] A.Y. Vinogradov, V.V. Stolyarov, S. Hashimoto, R.Z. Valiev. Cyclic behavior of ultrafine-grain titanium produced by severe plastic deformation. Mater. Sci. Eng. A 318.1 (2001): 163-173.

[19] R. Stevenson, J. F. Breedisu. Cyclic deformation of commercial-purity titanium. Acta Metall. 23.12 (1975): 1419-1429.

[20] T. Hama, H. Nagao, Y. Kuchinomachi, H. Takuda. Effect of pre-strain on work-hardening behavior of magnesium alloy sheets upon cyclic loading. Mater. Sci. Eng. A 591 (2014): 69-77.

[21] T. Hama, Y. Kariyazaki, N. Hosokawa, H. Fujimoto, H. Takuda. Work-hardening behaviors of magnesium alloy sheet during in-plane cyclic loading. Mater. Sci. Eng. A 551 (2012): 209-217.

[22] L. Wu, A. Jain, D.W. Brown, G.M. Stoica, S.R. Agnew, B. Clausen, D.E. Fielden, P.K. Liaw. Twinningdetwinning behavior during the strain-controlled low-cycle fatigue testing of a wrought magnesium alloy, ZK60A. Acta Mater. 56.4 (2008): 688-695.

[23] S. Begum, D.L. Chen, S. Xu, A.A. Luo. Low cycle fatigue properties of an extruded AZ31 magnesium alloy. Inter. J. Fatigue 31.4 (2009): 726-735.

[24] Titanium and titanium alloys -- Sheets, plates and strips. Japanese Industrial Standards, H 4600 (2012):

4-5.

[25] C.N. Elias, J.H.C. Lima, R. Valiev. Biomedical applications of titanium and its alloys. Jom 60.3 (2008): 46-49.

[26] M. Niinomi. Recent metallic materials for biomedical applications. Metall. Mater. Trans. A 33.3 (2002): 477-486.

[27] C. N. Eliasa, M. A. Meyers, R. Z. Valiev, S. N. Monteiro. Ultrafine grained titanium for biomedical applications: An overview of performance. J. Mater. Res. Tech. 2.4 (2013): 340-350.

[28] R.R. Boyer. Attributes, characteristics, and applications of Titanium and its alloys. Jom 62.5 (2010): 21-24.

[29] S. Bouvier. Characterization of strain-induced anisotropy in Titanium at large strains under monotonic and Bauschinger loading. PARIS-13 UNIV VILLETANEUSE (FRANCE), 2010.

[30] J.R. Helliwell. Macromolecular crystal twinning, lattice disorders and multiple crystals. Crystallography Rev. 14.3 (2008): 189-250.

[31] T. Hama, H. Takuda. Crystal plasticity finite-element simulation of work-hardening behavior in a magnesium alloy sheet under biaxial tension. Comp. Mater. Sci. 51.1 (2012): 156-164.

[32] I. Shimizu, N. Tada, K. Nakayama. The influence of strain path on biaxial compressive behavior of az31 magnesium alloy. Inter. J. Mod. Phys. B 22.31n32 (2008): 5844-5849.

[33] H. ALkhazraji, E. El-Danaf, M. Wollmann, L. Wagner. Enhanced fatigue strength of commercially pure ti processed by rotary swaging. Adv. Mater. Sci. Eng. 2015 (2015).

[34] M. Niinomi. Mechanical properties of biomedical titanium alloys. Mater. Sci. Eng. A 243.1 (1998): 231-236.

[35] M. Battaini, E.V. Pereloma, C.H.J. Davies. Orientation Effect on Mechanical Properties of Commercially Pure Titanium at Room Temperature. Metall. Mater. Trans. A 38.2 (2007): 276-285.

[36] H. Becker, W. Pantleon. Work-hardening stages and deformation mechanism maps during tensile 
deformation of commercially pure titanium. Comp. Mater. Sci. 76 (2013) 52-59.

[37] N. Benmhenni, S. Bouvier, R. Brenner, T. Chauveau, B. Bacroix. Micromechanical modelling of monotonic loading of CP a-Ti: Correlation between macroscopic and microscopic behavior. Mater. Sci. Eng. A 573 (2013): 222-233

[38] M. Ishiki, T. Kuwabara, Y. Hayashida. Measurement and analysis of differential work hardening behavior of pure titanium sheet using spline function. J. Mater. Process. Tech. 80 (1998): 517-523.

[39] G. Murasawa, T. Morimoto, S. Yoneyama. Nucleation and growth behavior of twin region around yield point of polycrystalline pure Ti. Exp. Mech. 52.5 (2012): 503-512.

[40] T. Hama, N. Kitamura, H. Takuda. Effect of twinning and detwinning on inelastic behavior during unloading in a magnesium alloy sheet. Mater. Sci. Eng. A 583 (2013): 232-241.

[41] T. Hama, T. Mayama, H. Takuda. Deformation behavior of a magnesium alloy sheet with random crystallographic orientations under various loading paths. Romanian J. Tech. Sci. Applied Mech. In press.

[42] T. Hama and H. Takuda. Crystal plasticity finite-element simulation of deformation behavior in a magnesium alloy sheet considering detwinning, Steel Research International, 2012 Special Edition, $1115-1118$.

[43] O. Bouaziz, N. Guelton. Modelling of TWIP effect on work-hardening. Mater. Sci. Eng. A 319 (2001): 246-249.

[44] O. Bouaziz, S. Allain, C. Scott. Effect of grain and twin boundaries on the hardening mechanisms of twinning-induced plasticity steels. Scripta Mater. 58.6 (2008): 484-487.

[45] X.Y. Lou, M. Li, R.K. Boger, S.R. Agnew, R.H. Wagoner. Hardening evolution of AZ31B Mg sheet. Int. J. Plasticity. 23.1 (2007): 44-86.

[46] S.H. Park, S. Hong, W. Bang, C.S. Lee. Effect of anisotropy on the low-cycle fatigue behavior of rolled AZ31 magnesium alloy. Mater. Sci. Eng. A 527 (2010) 417-423. 